\title{
DISTINGUISHING THE USES, FUNCTIONS, AND PURPOSES OF CLASSIC MAYA "CHOCOLATE" CONTAINERS: NOT ALL CUPS ARE FOR DRINKING
}

\author{
Jennifer Loughmiller-Cardinal \\ Department of Chemistry, University at Albany, 1144 Life Sciences Building, Albany, New York 12222
}

\begin{abstract}
Traditionally, cups have been the primary artifact through which beverage consumption has been inferred or defined, regardless of the numerous other artifacts that may be involved in beverage production, preparation, and service. Conversely, not all cup-shaped artifacts were intended to be used as drinking vessels, nor were all of them necessarily intended to contain a liquid. For the Maya Classic period (A.D. 250-900) decorated cylinder vessels in particular, this paper shows that the residues of their former contents do not agree with epigraphers' interpretations of what have been taken as self-referential statements about their contents and uses. This disparity between expectations and data indicates that we have misunderstood both the vessels and the text, and perhaps that we have failed to recognize one or more classes of vessels. The research presented here suggests that we need to rethink the generally accepted interpretation that all cylinders were drinking vessels and that those that are currently referred to as "chocolate" vessels were never used for the consumption of liquid cacao beverage. These results provide a new context for interpreting the use, function, and purpose of these vessels. Methods drawn from both the natural and social sciences are used to relate archaeological materials, residues of their ancient contents, their hieroglyphic texts, ceramic imagery(/iconography), and past behavior. This diversity of methods accentuates that combining data from all these sources constrains the interpretations of each, and shows that our initial expectations about vessels with hieroglyphic tags have been overly specific. Determining the functions and uses of these vessels is not as simple as we have been supposing, but distinctions that prove to be relevant give us access to more complex systems of cultural practice.
\end{abstract}

\section{INTRODUCTION}

Prior to the application of residue analysis, the uses of Classic (A.D. 250-900) Maya vessels had been inferred largely by analogies from ethnographic or ethnohistorical descriptions, often in terms of, or in connection with interpretations of, iconographic images and/or texts that adorn many elite vessels of this period. Residue analysis has made it possible to empirically determine what substances many Classic Maya vessels contained at various stages of their life cycles, but often, even typically, it is for relatively few issues that enough objects have been analyzed to establish larger patterns in the data for formally similar, but differently used, artifacts or to recognize distinct regional uses of artifact types. This paper presents evidence of one such emerging pattern. The residue analyses summarized here demonstrates that the ornate Classic-period Maya cylinder vessels that have been interpreted for the past 30 years as vessels from which to drink chocolate cannot have had that use, intended or actual, and analyzes the physical properties, iconography, hieroglyphic texts, and former contents of the vessels to suggest a range of alternative interpretations.

The exclusive focus of this paper is a subset of the Classic Maya cylinder-shaped vessels, regularly found in elite burial assemblages, bearing the hieroglyphic text known as the "Primary Standard Sequence" or PSS (see Coe 1973; Mora-Marín 2008; Stuart

E-mail correspondence to: chuljenn@ @otmail.com
1989). It is now sometimes referred to as the "Dedicatory Formula" (Mora-Marín 2001:104; Stuart 2005:5), but in the absence of explicit/direct evidence for a dedicatory function (cf. Kaufman and Justeson 2009:228) this paper uses Coe's original, neutral term.

This PSS text category was identified by Michael Coe (1973) based on a comparative analysis of a large number of vessels. Coe showed that the PSS was a standard passage, with alternative instantiations, that occurred in a standard order across a large number of vessels. Numerous studies have since contributed to the reading and interpretation of every component of the text (Boot 1997, 2003, 2005; Houston et al. 1987, 1989; MacLeod 1990; Mora-Marín 2003; Reents-Budet et al. 1994; Stuart 1988, 1989). A critical breakthrough was the demonstration by Houston et al. (1989) that one component tends to correspond with the form of the vessel on which it occurs - for example, 'u lak ('u-la-ka), "his/her plate", appears on flat-bottomed shallow vessels. The corresponding term on the cylinder vessels discussed in this paper is $y$ - $u k^{\prime}$-iib' (typically spelled yu-k'i-b'i), "his/her drinking vessel," typically followed by a category of person such as keleem, "youth." The other most intensively investigated component of the PSS was the demonstration that this term was followed by words for foodstuffs, e.g., 'uul ('u-lu), "corn gruel"; most commonly mentioned in these texts is kakaw, "cacao," in varied spellings (e.g., Beliaev et al. 2010; Hull 2010; Kaufman and Justeson 2006, 2007; McNeil 2006; Stuart 1988, 2005, and especially 2006). 
Although other genres of text are present on such cylinder vessels (see Loughmiller-Newman 2008; Reents-Budet et al. 1994), this research specifically addresses those vessels bearing the PSS text and focuses on those with PSS texts that include food names. The standard and seemingly straightforward interpretation of these vessels, which typically bear a specific reference to someone's drinking vessel and to cacao, and which are similar in form to known drinking vessels, is that these were elite personal objects for the consumption of beverages containing cacao. The PSS texts on these vessels are generally interpreted as saying something like, "Someone's specified type of vessel for specified food/ drink" - most often, "Someone's drinking vessel for cacao." Mayanists colloquially refer to them as "chocolate pots" or "chocolate vases," having long considered their function a settled matter.

This consensus view, however, does not account for the physical properties of vessels of this form, among them the residues of the former contents of these vessels. To date, not a single positive identification of cacao has been reported for any PSS-labeled cylinder vessel of this type; the only seeming success of this sort was the discovery of cacao residues in a radically different vessel type (Hurst et al. 1989). As part of an ongoing residue-analysis project, I have drawn residue samples from 70 of this specific type of vessel, about equally from vessels in archaeological context and those in museums and private collections. Not one tested positive for the key residues that should be present had they been used as drinking vessels for a liquid cacao mixture. Even taking into consideration the intrinsic difficulties of chemical residues analyses (e.g., preservation, contamination, sampling variability, and error), it is highly improbable that the lack of identifiable residues in any of the samples is a spurious result. Cacao has been successfully identified throughout the Maya area in other vessel forms and contexts using similar methods of residue analysis, and some sort of vessel obviously was being used for consuming such beverages.

To reconcile this apparent mismatch between what had seemed a clear textual statement of an artifact's function and the empirical determination that none had contained the beverage implied by that function, it is necessary to reassess the multiple lines of evidence that led cacao residues to be expected in these vessels and to reconsider the basis of functional inference itself. The following discussion examines the text of the PSS and its referents, the iconography of vessels on which they occur, depictions of such vessels in representational art, and the physical characteristics of the cylinder vessels in terms of the results of the residues analysis. This examination reveals certain inherent problems with using vessel form as the primary basis for analogical comparison, functional classification, or functional interpretation that are addressed here by considering the interaction of artifact use and purpose.

\section{RESEARCH MOTIVATION AND DESCRIPTION OF SAMPLE}

The research presented here addresses Maya cylinder-form pottery vessels from the Classic period (A.D. 250-900), often referred to interchangeably as "cups" or "vases." These vessels vary in size, shape, and proportions, but I refer to a vessel as a "cylinder" when the diameter of the base and mouth are less than the height (height $>$ radius; Figure 1). Cylinder vessels that are ornately decorated and bear a PSS text I refer to as "labeled"; they commonly are of fine, thin-walled construction. Undecorated cylinders tend to be smaller in overall size, with thicker construction than their decorated counterparts. The labeled cylinders, the decorated cylinders

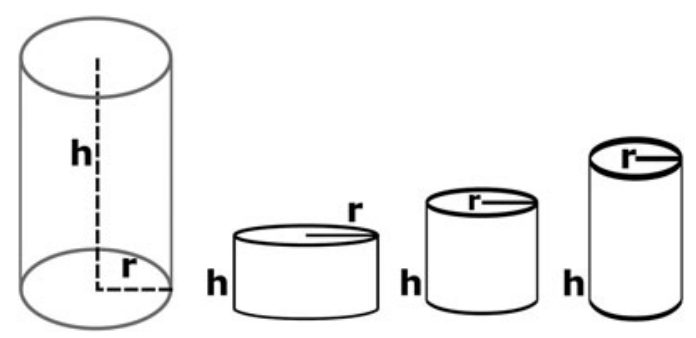

Figure 1. The height of the cylinder used here is equal to or greater than the diameter. Drawing by author.

without label, and the undecorated cylinders are considered formally similar in terms of standard systems of vessel classifications (i.e., decoration-based subcategories within a broad and morphologically variable "cup/vase" class). It cannot be assumed a priori, however, that they all served the same purposes or were used in the same manner, and data presented below show that this is, in fact, unlikely.

The data discussed below are part of an on-going study of burial goods and ritual items of the Classic Maya elite. Most of the vessels in the sample come from controlled archaeological excavations: some were examined in situ, recovered in recent or ongoing excavations such as those at Calakmul, Mexico; others were analyzed in archaeological museums housing artifacts recovered in earlier controlled excavations. The sample also includes comparable types of vessels now housed in public institutions such as the Kislak Collection at the Library of Congress. The selection of the vessels is non-random, being limited to complete or nearly complete vessels found mostly in ritual or burial contexts. Burial vessels tend to be better protected, and so are better preserved than those from other archaeological contexts, making them generally the most useful for analysis and also the most coveted for museum collections.

Seventy cylinder vessels were selected for analysis. All are complete or nearly complete; only vessels with intact rims and/or bases (at least 90 percent intact or better) are included in the sample. Sixty-one ( 87 percent) of these bear a text. Among these texts, at least twenty-three (37 percent) mention foodstuffs; and five ( 8 percent) are too eroded to determine whether they are PSS texts or, if so, whether they mention foodstuffs. The 70 cylinders were divided into three size groupings: nine small $(\leq 12 \mathrm{~cm}), 37$ medium $(>12 \mathrm{~cm} \leq 20 \mathrm{~cm})$, and 24 large $(\geq 20 \mathrm{~cm})$. The thickness of the vessels fell between 2.8 and $6.8 \mathrm{~mm}$, with an average thickness of $4.7 \mathrm{~mm}$. These cylinders represent a wide variety of Classic-period styles, but regionally this sample favors the Calakmul sphere of influence where this research began.

The addition of residue analyses to the studies of archaeological materials has been a notable change for our field. This information often clarifies behaviors in ways that we might have suspected from the material remains, and in other cases challenges us to rethink our interpretations. Unfortunately, archaeologists are confronted with an extensive list of agents (both natural and human-assisted) working against preservation of analyzable residues (see, for example, Schiffer 1987; Evershed 2008). The limitations of residue analyses cannot be adequately itemized here, but it is relevant to this study to acknowledge that lack of residues reported here (possibly also pertinent in the studies indicated below), preservation, or contamination maybe at fault for some of the lack of identifiable residues. As this study advances, it is the intention of the author to expand this 
research into other archaeological contexts, as well as other Classic Maya regions, to explore the diachronic and spatial boundaries of the interpretation provided here.

It has been surprisingly rare to find agreement between label and residue content. Although cacao has been successfully identified throughout the Maya area, there has never been a positive identification of cacao in a PSS-labeled cylinder vessel. The only identification of cacao residues in a labeled vessel to date has been the Rio Azul lock-top storage vessel (Hall et al. 1990; Hurst et al. 1989). Since the 1990 Rio Azul discovery, matching text and residue content was not found again until 2011, with the identification of tobacco residues in a flask bearing a labeling text indicating tobacco (see Loughmiller-Cardinal and Zagorevski 2016; Loughmiller-Newman 2012; Zagorevski and Loughmiller-Newman 2012). At the time of this research, these two vessels were the only proven examples of matching label and content. Both the tobacco flask and the Rio Azul lock-top vessel are, however, storage containers and are exclusively decorated with text without image. So far, no confirmed match between label and content has yet been found for any direct consumption vessels.

The rarity of empirical evidence for matching content and label, and the lack of any similar evidence from any direct consumption vessels, instigated the research described here. The study presented here reports on research I began in 2007, and should be considered alongside residue analyses reported by other Maya scholars since the 1980s (especially note the lack of cacao found in any hieroglyphically marked cylinders; see, for example, McNeil 2006). Based on the empirical evidence that the PSS-labeled cylinder vessels do not appear to have held a cacao-based beverage, these findings challenge the standard interpretation for these vessels by demonstrating that: (1) that the PSS on the cylinders is not acting only as a label; (2) the content of the cylinder were not determined by text and/or label; and (3) the highly decorated and/or labeled cylinders were not used for direct consumption of a cacao-based liquid.

\section{Chemical Residues Analysis}

To address cacao residue properly, it should be noted that cacao beans that were ground for consumption in the Classic period were not likely stripped of their butterfat, and therefore not processed to a dry powder, resulting in an oily, powdery pulp. To suspend this ground cacao into a liquid concoction, either hot water or vigorous mixing with some liquid would need to occur (see Powis et al. 2002 and Green 2010 for additional details on preparation); thus, a cacao beverage was never purely cacao. Once mixed, a cacao beverage would begin to separate, with the oil pooling on the top of the liquid and the cacao grit and particles settling to the bottom. As the Maya had pottery, rather than high-fired kiln ceramics, the porous vessel body would necessarily absorb a portion of a liquid into the fiber of the container (Evershed 2008: 904, see also Charters et al. 1993; Stern et al. 2000; Green 2010).

The sampling strategy for the collection of residues was to target the interior bottom and sides, where residues would likely be the most densely concentrated. Samples were also taken of the ceramic fiber (the inner core of the profile) when possible. All sampling was done on location, whether in the field or museum. All reasonable efforts and common laboratory standards were employed to limit contamination. Sampling was conducted with stainless steel tools, which were sterilized before and after every sample. The samples were then placed in sterile glass containers and labeled appropriately. The organic analyses were conducted at Rensselaer Polytechnic Institute with the assistance and direction of Zagorevski.

During the organic evaluations, the collected samples were manually ground into thin powder on an aluminum mortar and pestle. A $\sim 0.5 \mathrm{~mL}$ by volume measure of the powder was placed in a polypropylene vial. The organic compounds were extracted from the powder using a methanol-methylene chloride (1:1) mixture. The vial was tightly sealed with a screw cap, and shaken for approximately two hours on an automated shaker. The mixture was left overnight, allowing solution and solids to separate. The solution was removed, centrifuged, and filtered using Millipore filters. The solvent was evaporated on a centrifuge vacuum evaporator. The samples were re-dissolved in $10 \mu \mathrm{L}$ of the methanol-methylene chloride (1:1) mixture before being analyzed by gas chromatography - mass spectrometry (GCMS) methods (Zagorevski and Loughmiller-Newman 2012; see also Hurst 2006; Hurst et al. 1989, 2002).

For the GCMS portion, a Shimadzu QP5050A mass spectrometer with a GC-17A gas chromatograph was used for analyses. Separation of volatile components of the mixtures was performed on a Restek Rxi-5 ms (5 percent diphenyl, 95 percent dimethyl siloxane) $30 \mathrm{~m} \times 0.25 \mathrm{~mm}$ column, pore size $25 \mu \mathrm{m}$, using the following temperature gradient: initial temperature $60{ }^{\circ} \mathrm{C}$, hold at $60{ }^{\circ} \mathrm{C}$ for 2 minutes, followed by a linear gradient to $250{ }^{\circ} \mathrm{C}$ at $20{ }^{\circ} \mathrm{C} / \mathrm{min}$, linear gradient to $325^{\circ} \mathrm{C}$ at $10{ }^{\circ} \mathrm{C} / \mathrm{min}$ with a total analysis time of $24 \mathrm{~min}$. One $\mu \mathrm{L}$ of sample was injected into the injector port, which was held at $250{ }^{\circ} \mathrm{C}$. The detector temperature was $250{ }^{\circ} \mathrm{C}$. The mass spectrometer was operating in electron ionization mode in the mass-to-charge range from $\mathrm{m} / \mathrm{z} 40$ to $\mathrm{m} / \mathrm{z} 600$ at a scanning speed of $\sim 0.3$ seconds per scan. The instrument control, data acquisition, and data processing were performed using Shimadzu GCMS solutions software (version 1.20).

Microfossil silica phytoliths were targeted for the inorganic evaluations. The following procedure is a general method of separation by density used to isolate $\mathrm{SiO}_{2}$ siliceous phytoliths from their deposit matrix. Samples were lightly ground into small particles with a stainless aluminum mortar and pestle. The static bonds of phytoliths with clay particles were broken with laboratory detergent Ethylene diamine tetra acetic (EDTA) soaked and agitated. The sample was fully submerged in nitric acid $\left(\mathrm{HNO}_{3}\right)$, agitated, allowing organic matter to be dissolved or destroyed. The sample was centrifuged and the supernatant drained, more $\mathrm{HNO}_{3}$ was added, and the process was repeated. Heavy floatation was conducted with Zinc iodide $\left(\mathrm{ZnI}_{2}\right)$ and hydrochloric acid $(\mathrm{HCl})$. The phytoliths were recovered from the liquid, dried, and slide-mounted. Peremount was used for this analysis. Samples were examined with a Nikon Optiphoto-pol at 400× magnification $(20 \mu \mathrm{m})$.

At no point were any of the alkaloid biomarkers of cacao chemically identified, nor were any microfossils of cacao identified during inorganic evaluations. Both the organic and inorganic analyses would also have been able to identify other potential contents. Maize phytoliths were also sought, but were not found in sufficient numbers to argue more than natural contamination. Microscopic phytoliths can be easily introduced by natural conditions (wind or water), or through contamination introduced during excavation and handling (i.e., hair and clothing). Maize was once extremely common, and therefore the contamination was expected.

I also did not find any evidence of other foodstuffs or drugs that include alkaloids (e.g., chili pepper, tobacco, buffo toxin, and psilocybin mushrooms). From the inception of this research, contents 
other than those specified by hieroglyphic text or indicated by iconography were sought in addition to the suggested contents. Methods used for ancient residues are not able to infinitely examine all potential residues, and so reasonable limitations were established to explore for the greatest possible range of significant or non-daily foods (although some would, in fact, be potentially identified). Therefore, the organic analyses primarily targeted alkaloids, which are compounds found in a myriad of intoxicants, ritual and recreationally consumed foodstuffs, and cacao.

\section{PHYSICAL CHARACTERISTICS OF THE CYLINDER VESSELS}

The PSS-decorated cylinders are not uniform in size, and many of these vessels do not seem ergonomically designed for reasonable personal use for drinking. Although liquid foodstuffs may be consumed from a wide variety of vessel forms, the sizes and configurations typical of the cylinders certainly would render them awkward and cumbersome for regular consumption. Some cylinders are very large, measuring more than 20 centimeters in either diameter or height, and would be exceptionally difficult for an individual to wield to drink directly. Others are tall and slender, more than 30 centimeters high and less than 10 centimeters in diameter with small apertures. Some are heavy enough that, if one were to pour a liter or more of liquid cacao into them (weighing approximately 4 pounds, not including the vessel), they would be extraordinarily difficult to maneuver. Others are of a medium height $\leq 20 \mathrm{~cm}$ with a much larger mouth featuring diameters in excess of $>20 \mathrm{~cm}$, again making them difficult to manipulate without significant risk of spillage. A few examples, such as the rectangular vessels (Figure 2), are formed in such a manner as to defy a cup-like designation. Such irregularly shaped vessels would be difficult to use as drinking vessels. No rectangular or overly large diameter vessels were examined for residues in this study.

Although I cannot argue that such vessels could not have been used as drinking vessels, as many shapes and sizes of vessel can be used for drinking, the variations in physical characteristics of the cylinders tend towards the unwieldy and do not seem to suggest that ease of use as a drinking vessel was likely the foremost

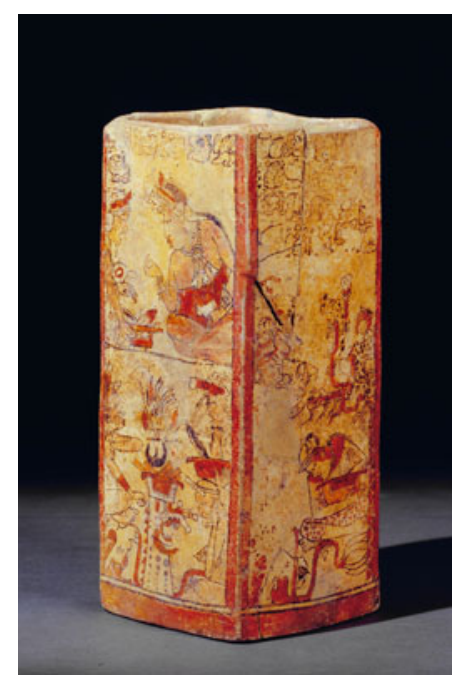

Figure 2. Example of a square vessel. (Kerr no. K5113). Photograph (C) Justin Kerr. consideration in their design and purpose. When discussing this vessel form, its association with elite behaviors, and as a vessel otherwise synonymously identified as a drinking cup, then their design is worth considering towards a clearer understanding of their purpose. There are, in fact, very few images depicting elites in the act of drinking. From the examples that we have of elites drinking (e.g., Figure 3), the vessels depicted are either undecorated or minimally decorated small/medium bowls or cylindrical vessels that are not much taller than one-and-a-half hand spans, roughly falling into the medium size range noted above. This approximation is based on using hand depicted in the art as a scale for the relative size of the vessel. Aside from the images of figures attempting to drink from the large ollas, there are no images that depict anyone drinking from vessels other than the small, undecorated bowls and small-to-medium, undecorated (or limited decoration) cylinders.

Maya vessels were not kiln fired, which resulted in a permeable and porous clay body lacking significant vitrification due to low firing temperatures (see Rice 1989:231, 350-351). Although a number of surface treatments were used that can limit this porosity (chiefly, burnishing and slip coating), many vessels, including the cylinders, remain highly porous (Young and Stone 1990). Absorption of liquids into the porous body of these vessels is nearly immediate, and can be substantial in some cases. The clay fabric itself would necessarily retain traces of liquid contents due to the absorption (Evershed 2008).

Experimental cylinders were created for general purposes of evaluation and experimentation. Natural clay vessels with calcium temper were handmade by coiling and paddling into rough cylinder shapes. These were air dried for a week, then open fired at less than $800^{\circ} \mathrm{C}$. Experimental trials confirmed observational data acquired from actual vessel handling that an immediate quantity of liquid is absorbed into the vessel fabric. The amount absorbed, depending on thickness, surface treatment, and the composition of the liquid can be substantial, with 20 to 30 percent loss; this is for a new vessel and an 85 percent water-based beverage. Absorption through the vessel to the exterior was observed. This suggests that exterior decoration could have been affected by the liquid, as well as indicating that repeated use would lead to the erosion of the exterior decoration by seepage and handling in that state (see Loughmiller-Newman 2012:241; Schiffer 1988; Skibo 1992).

The interior attrition or wear patterns on all the Maya cylinders examined were also inconsistent with a vessel that had repeatedly held liquid. Some vessels do show signs of liquid rings from postdepositional flooding, but these are easily identified as such. There are no traces on any of the vessels of any darkening expected from a beverage containing heavily staining cacao and oil, although time and degradation may eliminate stains of this form. Nor is there any indication of interior liquid ring lines that would result from evaporation or absorption of a liquid. This observation was echoed by Justin Kerr (personal communication 2014), photographer of the Kerr Vase Rollouts, who has handled thousands of these cylinders; there are no descriptions of such wear in any published examinations of such vessels. While many of the well-known cylinders are without provenience, have been mended, and/or have been retouched, the lack of use-ware consistent with drink containment and handling is not present on the archaeologically sound vessels, either.

The interiors of the cylinders do show a minute amount of interior wear, mainly in the form of light vertical lines and, more commonly, isolated areas of abraded wear. The vertical markings on the sides of the vessel are consistent with attrition caused by a soft bone or wood tool. This is suggested by the downward angle at which 


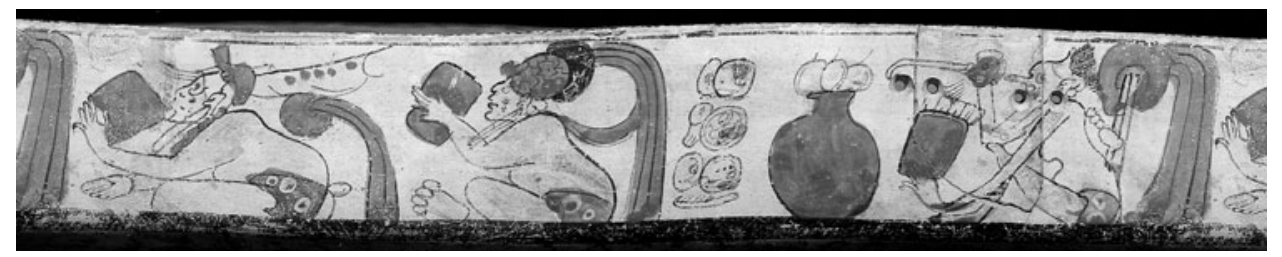

Figure 3. Example of individuals drinking. Note size of hand in relationship to vessel (Kerr no. K4377). Photograph (C) Justin Kerr.

pressure was applied and the light grooving that resulted from the movement. These marks are inconsistent with those caused by animal, insect, or natural degradation (Schiffer 1987). Other isolated areas of wear in the form of light pocking are more uniformly found around the interior and on the base of the vessel, notably on the lower portions of the interior walls. This suggests that something both non-liquid and slightly abrasive was in contact with the surface.

\section{LINGUISTIC AND CONTEXTUAL EVIDENCE}

The vessels discussed here were sumptuary goods (as elaborated below). The PSS-labeled cylinders were not common items, such as utilitarian storage vessels that might simply be labeled as "for sugar," but highly significant elite paraphernalia. Based on our reading of the texts, the Mayas discussed a very limited number of topics and named very few items. Basic household items, daily events, and common people are never among the items mentioned. Although some "common" items do appear in images and less frequently in the text, the context in which they appear (i.e., whether shown in the image, the fact that it is written on an elite vessel, or the archaeological context) makes them exceptional and thus cannot be considered mundane in these instances.

The PSS is typically, but not exclusively, written around the exterior top lip of the vessel and is generally in the largest script (i.e., compared to other text present on the vessel). Since this text is visually separated from the any other decoration or text, the PSS has been assumed to reflexively address the vessel itself rather than the depicted scene below. Although the PSS does follow a certain predictable pattern, there are many variations and not all parts of the text are always present. The reader is directed to the work of Boot (2003), Grube (1986, 1990), Houston (1989), MacLeod (1990), Mora-Marín (2004, 2008), Reents-Budet et al. (1994), and Stuart (1989, 2005, 2006) for such examples. Typical or generic examples of the PSS on the vessels follow the template: (1) Introduction: 'alay, "there is here" 't'ab'ab(i)(?), (2) Surface decoration painting or carving: 'ich(?) "already" 'u-tz'ihb'-naj-al(?) "his/her/its written/painted surface," (3) Folk classification of vessel: e.g., y'uk'iib', "his/hers/its for the drinking," (4) Foodstuff: e.g., te'el kakaw, "forest cacao," (5) Titles/Name: e.g., keleem 'aajaaw, "young lord."

This text is not exclusive to vases and has been identified on other classes of vessels as well as on stone monuments, jewelry, and clothing (Stuart 2006). The PSS takes its fullest form in the Classic period, but the beginnings of the PSS can be traced to the Early Classic (A.D. 200-500; see Mora-Marín 2004, 2008:21-24). I do not believe that we can yet sufficiently identify the full intention or function of this text, and for that reason I will continue with the terminology "Primary Standard Sequence" or "PSS" as a generic identification.

Among the textual references to foods in the PSS, cacao and maize are the two most common foodstuffs stated. Frequently, these foodstuffs have modifiers or additions that seemingly indicate something specific about their form or quality. The texts that indicate cacao have received the most attention. Given the cup-like shape of the cylinders, the references in the PSS to cacao, and the use of a folk classification of 'uk'iib', "his/her/its drinking cup," it seemed reasonable to conclude that these vessels were the objects used to consume a cacao beverage. In 1989, this interpretation received what appeared to be direct support from a vessel found in Rio Azul, Guatemala (Hurst et al. 1989).

The Rio Azul vessel is labeled with hieroglyphic text specifying cacao (twice), and tested positive for theobromine, one of the chemical biomarkers of cacao. The following 30 years provided a great many successful discoveries of cacao residues in a variety of containers (such as Crown and Hurst 2009; Colas et al. 2002; Henderson et al. 2007; Hurst et al. 2002:98; Powis et al. 2002, $2007,2008,2011)$. These discoveries have shown that cacao was consumed by the Olmec, was found in archaeological contexts from Honduras dating to earlier than 1150 B.C. (Henderson et al. 2007; Joyce and Henderson 2007), and was present still earlier in Mexico from contexts dating to around 1800 B.C. (Powis et al. 2007). Remarkably, theobromine and theophylline (alkaloid biomarkers of cacao, excepting of caffeine, can be a problematic biomarker) were found to be viable for thousands of years.

The Mayan word kakaw, "cacao," equally refers to the tree itself, its beans, and foodstuffs prepared from it. Kakaw, or kakawa-tl, in Nahua, as used in the early ethnohistorical documents, refers to beverages that are even partially composed of cacao regardless of amount. "Even today in some Mayan languages, such as Tzotzil [Laughlin 1975: 176] and Q'anjobal [Balam, personal communication to Kaufman and Justeson 2005], the word for cacao is used to name a drink made from it" (Kaufman and Justeson 2003:1104, 2006:136). I will be using the word cacao to refer to the tree as well the bean and ground cacao bean product consumed by the ancient Maya. Although often called "chocolate" even in some references to ancient uses, that term is inaccurate for this period. Chocolate refers specifically to roasted and ground cacao seeds, a cacao-based product, and we are not currently able to determine specifically how cacao was prepared during the Classic period, as opposed to how it is commonly done now.

\section{Hieroglyphic Text}

If a foodstuff is named in the PSS, it is within the framework of anywhere between three and 20 or more surrounding glyphs. Named foodstuffs are not always present in the PSS, however, and are only found on approximately one-third of known PSS-labeled vessels. The foodstuffs named are from a variety of cacao and maize products. The PSS itself typically contains the folk classification of vessels, the names of patrons, and sometimes the names of the artisans. It is generally recognized that there are occasional crossovers between folk names and vessel form (such as lak, "plate," also found on Jade plaques). Foodstuffs in the PSS, such as kakaw, are not necessarily exclusive to one vessel form (form 
Table 1. Cacao variations known for the PSS, adapted from Kaufman and Justeson (2007:33) including this author's additions.

\begin{tabular}{|c|c|c|}
\hline Group & Transcription & Reading and Notes \\
\hline \multirow[t]{9}{*}{ Kakaw "Theobroma cacao" } & kakaw & $\begin{array}{l}\text { "cacao" without modifiers indicating variety, with a default reading } \\
\text { unknown to us }\end{array}$ \\
\hline & $<$ tzi:h kakaw & "raw/unripe cacao" \\
\hline & $<7 \mathrm{a}($ :)ch' kakaw & "fresh/new/wet cacao" \\
\hline & k'an kakaw & perhaps "yellow Theobroma cacao," if not "ripe cacao" \\
\hline & $<$ Yut k'an kakaw & "lucky yellow/ripe cacao" \\
\hline & k’i:n (or k'ihn) kakaw & perhaps "sun Theobroma cacao," if not "hot cacao drink" \\
\hline & te7-e:1 kakawa & "tree cacao, Forrest" \\
\hline & $<$ tzi:h te7-e:1 kakaw & "raw/unripe tree cacao" \\
\hline & $<7 a: j a: w$ te7-e:1 kakaw & "lordly tree cacao" or "white sapote and cacao" \\
\hline \multirow{4}{*}{$\begin{array}{l}\text { Varieties of cacao modified by place names } \\
\text { and untranslated phrases }\end{array}$} & $<$ wi-ti-ki. kakaw & "Copan(?) cacao" \\
\hline & $<$ ko-xo-ma mu-lu $>$ kakaw & $\ll[$ reading unknown] cacao » \\
\hline & $<5-k a b ’$ kakaw & "Ixtutz cacao" (see Beliaev et al. 2010 who argue for "five honey") \\
\hline & $<$ SA7(-la) kakaw & $\begin{array}{l}\text { "Naranjo cacao" (see Beliaev et al. } 2010 \text { who argue this is not the name of } \\
\text { Naranjo but rather "gruel like cacao") }\end{array}$ \\
\hline \multirow[t]{2}{*}{ Combined ingredients of cacao drink } & $<7$ ixi:m [and] kakaw & "maize with cacao" \\
\hline & $<7 i x i: m$ [and] te7-e:1 kakaw & "maize with tree cacao" \\
\hline Possible reference to drinks, secondarily & $<$ k'ihn kakaw & "hot cacao drink" This term might be / k'i:n kakaw/ "sun cacao" rather than \\
\hline listing ingredients & & "hot cacao" and therefore be a variety of Theobroma cacao \\
\hline Possible indication of seed of kakaw & $<$ y-ut-al kakaw & $\begin{array}{l}\text { "seeds of cacao" (see Mora-Marín } 2004 \text { who argues this is "its/his/her } \\
\text { finished cacao"; also Beliaev et al. 2010, "fruity cacao") }\end{array}$ \\
\hline Theobroma bicolor (other species) Pataxte? & $<$ te7-e:1 b'ahlam kakaw & "tree or forest jaguar cacao" \\
\hline
\end{tabular}

indicted by folk name). Kakaw, for instance, is found on forms other than cup-shaped vessels. Finally, the PSS may also be written on clothing, monuments, and jewelry (Mora-Marín 2004; Stuart 2005). These latter texts tend to be shortened variants of the PSS, and follow more along the lines of name-tagging practices with the introduction, named item, and date (see Stuart 2005).

The foodstuffs named in the PSS nearly always indicate either cacao and/or maize with various modifiers or additives. Table 1 , adapted from Kaufman and Justeson (2007:33) including this author's additions, illustrates most of the cacao variations known for the PSS but is not intended to be exhaustive. As noted above, the word kakaw can be referring to the tree, pod, seed, or foodstuff with no specific indicator identifying which aspect of cacao is being referenced. Given the broadly cup-like shape of the cylinder vessels, as well as the textual reference to a drinking vessel and a foodstuff known to be an ingredient in a liquid beverage, the common understanding was that vessel text was indicating that the vessel had been used for that beverage. Since such a concoction would have left detectable residual remains (such as that found in other vessel forms; see for examples Colas et al. 2002; Crown and Hurst 2009; Henderson et al. 2007; Hurst et al. 2002:98; McNeil 2006; Powis et al. 2002, 2007, 2008) that are not present, the explanation must be that kakaw is: (1) referencing one of the other aspects of the plant rather than a subsequent beverage; (2) it is a symbolic reference to cacao use rather than the vessel's use; and/or (3) the text is commemorating an event where a specific cacao concoction was consumed.

The above are not full recipes, as cacao would have been only one component of the beverage: all of the foodstuff statements lack the liquid component to which they are added. The glyphic statements and modifiers of kakaw are more likely referring to the nature of the cacao seed or pod by color, growth, or location. Additionally, yutal is the most frequently occurring addition to kakaw that appears in the PSS. The generally accepted reading of yutal is the possessed form of a Ch'olan word for "seed" or "seeds" (MacLeod 1990; also Lacadena [personal communication 2005] in Beliaev et al. 2010: 258). Stuart (2006:188) and Kaufman and Justeson (2007:224), however, cite rare spellings as ' $u$-yutal, suggesting that the possessive marker for this word is $\mathrm{u}$ - and that $\mathrm{y}$ - is part of the noun root; this is inconsistent with words for "seed(s)." Justeson (personal communication 2017) suggests interpreting yutal as "contents" and u-yutal as "its contents," perhaps literally "what is inside something," as a lost Ch'olan cognate of proto-Tzeltalan *yut, "adentro // inside" (Kaufman and Justeson 2003:245), Tzeltalan languages being the closest relatives of Ch'olan. Colonial Yucatec yut and yutal, "bezoar stone(s)" (Ciudad Real 1984:f221v; Michelon 1976:424) may be related, as contents from inside the stomachs of some slaughtered deer, which are believed to have magical properties (Kaufman and Justeson 2007:224). Pío Pérez (1866-1877:411) gives <yutalceh $>$ as a term for bezoar stones from deer.

According to Kaufman and Justeson (2007:235),

yut(a:1) appears at about the same rate before 7ixi:m kakaw, before te7-e:l kakaw, and before 7ixi:m te7-e:1 kakaw - in each case, about once in four instances. This word yut(a:l) has one somewhat puzzling but potentially revealing association. Sixteen (70\%) of the 23 cacao vessels in Mora-Marín's database whose owner is labeled, 7i-tz'a-ti are among the 77 with yut(a:1) as the first modifier, while only seven are among 124 that lack it. This association is statistically significant $(\mathrm{p}=0.001)$.

The types of foodstuffs named in the PSS are commonly dried prior to preparation and consumption (e.g., cacao and maize), and in seed or dried form could have been reasonably stored in the highlydecorated vessels without damaging the decoration or the vessel.

The expression te'el is translated as "forest" (in Chol; Aulie and Aulie 1978:110) or "tree" (in Tzotzil; Laughlin 1975:333). Stuart (2006:194) has suggested this may be indicating "wild cacao" (literally "of-the-forest"), and most likely indicating uncultivated 
Theobroma cacao. K'i:n (or k'ihn) kakaw has been thought to indicate "sun or hot cacao." I suggest that this might be indicating Theobroma bicolor, commonly referred to as pataxte. Pataxte pods and seeds are very similar to those produced by cacao trees and are similarly processed and consumed (Kufer and McNeil 2006), but the tree is dissimilar in one key aspect: Theobroma bicolor (pataxte) will grow in full sun, while Theobroma cacao needs at least partial shade and cannot grow in full sun (Bronson 2014; Hellmuth 2010; Kew Science 2017). Several of the modifiers attached to cacao appear to be locations, possibly identifying specific orchards. "There are two clear examples [of location] and one likely example. One of these is the only modifier of kakaw in its phrase, and two of them immediately follow yuta:l and precede kakaw" (Kaufman and Justeson 2007:34), therefore "the seeds of 'location' cacao."

The term $t z i h$ frequently precedes cacao, though in other cases it stands on its own as a lone word. "The term tzih relates to the idea of 'raw,' 'fresh,' or 'pure' in many Mayan languages today, though the exact meaning is still somewhat in debate epigraphically" (Stuart 2006:194; from Stuart 2005:144-145; see also Reents-Budet et al. 1994:118). Kaufman and Justeson (2007:32) conclude that the word $t z i h$ in combination with cacao, "refers neither to a variety of the cacao plant nor to an ingredient in the drink. In the frequent phrase tzi:h(-i:l) kakaw 'raw cacao,' the word kakaw must refer to the cacao kernel or pulp - thus, to cacao as an ingredient and not as the name for a drink." If speaking about cacao beans, this may be indicating untreated beans in a stage presumably prior to the drying, roasting, and/or fermenting processes.

\section{Contextualizing the text}

If the "chocolate pots" were not used, and not unambiguously designed, as vessels for the actual drinking or holding of liquid cacao (as compared to the thicker bowls and cups where theobromine residues are found), then another discrepancy becomes apparent. The only known meaning of the word ' $u$ ''iib' (or ' $u c h$ ' $i i b$ ') is 'drinking vessel," which leads to its common reading as "a vessel from which one drinks." Furthermore, the Rio Azul pot (Stuart 1988), which also bears the ' $u k^{\prime}$ 'iib' label did contain cacao residues, is a thicker-walled storage container, neither a cup- nor vase-like vessel, nor designed for direct consumption. Conversely, the cylinder vessels labeled "drinking vessel" both did not contain cacao residues and were not likely used for drinking. Since both the labeled cylinders and the Rio Azul vessel bear ' $u k$ ' 'iib', our reading of the term appears to be misidentifying its reference. Logically, either the reading of
' $u$ ' 'iib' has a connotation other than "a vessel from which one drinks" or its presence in the PSS must be referring to some other drinking vessel that is in the possession of the elite individuals or types of individuals named as their owners and not the vessel on which the statement occurs.

As described above, the physical examinations of the vessels did not show use-wear patterns consistent with holding a liquid, but they did show indications of abrasion wear consistent with nonliquid contents and vertical tool striations. One possible explanation for these wear marks could be dried contents such as dried cacao seeds, which could have been measured out with a bone or wood tool. The seeds could then be readily ground and added to a drink base such as those named on the fermentation ollas (Figure 4), which are commonly shown in the scenes depicted on the body of the cylinders. A number of these scenes are on the same vessels that have PSS text including cacao. Cacao could then have been added only to the drink of the containing vessel's owner and subsequently consumed from a more common bowl or smaller cylinder cup. If held in a lidded cylinder, dry cacao seeds could be stored for longer periods than cacao in a liquid.

Contents of cacao in its dry seed form would be far more difficult to detect chemically in vessels than would a mixture of pulverized cacao suspended in some liquid, since the dried contents would not penetrate the vessel surface or body. Cacao seeds are encased in a hard shell covered in oils that would not degrade quickly and would, based on preliminary observations, leave scant traces. Further studies on the residues of cacao seeds in terms of maximum storage duration and residue expression require additional experimental evaluation and testing. The stored contents were probably not a cacao slurry, as prolonged storage would have resulted in layers of residue. Archaeological evidence is known, from one burial at Tikal, that at least some cylinder vessels had held cacao seeds: "[i]n the royal Tomb of the Jade Jaguar at Tikal, one of the polychrome Tepeu 2 Maya vases there had the remains of a 'souplike' material. It was dried out ... but the remains of the seeds were still quite visible" (Hellmuth 2010:1).

The modern process of extracting butterfat was not invented until 1828, when Coenraad Van Houten devised a method that removed the cacao butter from the chocolate liquor (Battcock and Azam-Ali 1998; see also Coe et al. 1996). We do not have direct evidence that the Maya produced a dry cacao powder. Even if they did have a means of extracting the butterfat, storage of the hygroscopic powder would have presented several key storage issues in the humid tropics. Additionally, a fully prepared Maya cacao beverage could not have

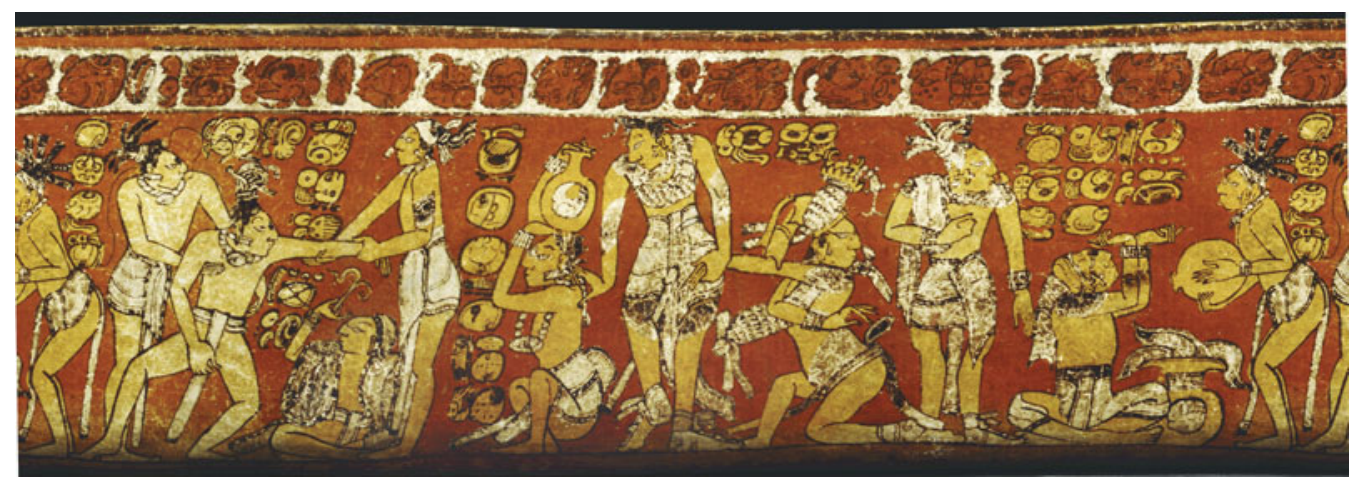

Figure 4. Example of kakaw in the Primary Standard Sequence (PSS), with image showing olla labeled chiih, "pulque" (Kerr no. K1092). Photograph (C) Justin Kerr. 
been stored for long without separating and spoiling. The highly significant drink was more likely produced just prior to consumption, thus ensuring the emulsion of the oily cacao into a liquid base to achieve the desired suspension. It would be more likely that cacao was left in bean form during transportation and storage.

From the images and associated texts, we see that large quantities of fermented beverages (e.g., honey/mead, maize/beer, and pulque) were being prepared and consumed. These beverages are shown as being consumed from cups and bowls. Some of these images and texts also occur on the same vessel on which kakaw is indicated in either the PSS or rim text. Cacao is not directly shown in the images, but only implied by the presence of a corresponding vessel form (i.e., a small cylinder vessel) or other iconographic elements. It is likely, then, that these small, undecorated vessels are the drinking vessels, rather than the decorated cylinders. Accordingly, small undercoated bowls and small thick cylinders are also found in the same burials where labeled cylinders have been recovered. These small vessels are the ones in which residues of cacao have generally been found (see Henderson and Joyce 2006:150; Hurst et al. 2002; McNeil 2006; Powis and Cheetham 2007; Powis et al. 2006, 2011). Further investigation into the correspondences of the decorated cylinder vessels and these small, undecorated vessels is warranted in order to test this hypothesis.

\section{Contextualizing the vessel}

A vessel that is designed to communicate the status of an elite or royal individual needs to be distinctive, and sumptuary rules or limitations restricting ownership enacted to keep the value and status of the exclusive item elevated. Those who are unable to own such objects would be aware of such restrictions, and they would identify the vessel as a significant emblem of the owner and/or the owner's status. The color palette and designs employed by the various cylinder-producing workshops are distinctly identifiable with a specific region (i.e., workshop or city-state; see Coe and Kerr 1998; Miller 1999; Miller and Martin 2004; ReentsBudet and Bishop 1998; Reents-Budet et al. 1994, 2000, 2010). These distinctive palettes are represented even when the vessels are depicted within other scenes, thus indicating the importance not only of the vessels themselves but also of their decoration (Figure 5). Furthermore, as described in 2008 (LoughmillerNewman 2008), most cylinders were decorated with a primary scene. Typically, this primary scene features the main figure surrounded by his accouterments of office and power, or a main scene of historical or mythological importance. It is possible that this main scene was the display side for approaching viewers (see Loughmiller-Newman 2008).

The cylinders were designed with the intention of being immediately recognizable, and to be displayed and viewed in such a way as to emphasize the primary subject of the scene and its eminence. Furthermore, in the depiction of these elite primary subjects there is a limited number of accouterments he or she possess, all of which are denoting elite status and rank. Such a vessel, which has limited utilitarian functions to perform and is less likely to be exposed to regular handling, can be made to be relatively fragile (e.g., extraordinarily thin and unwieldy). It can also be elaborately decorated without fear of rapid degradation from handling and use. Since a significant function of such signaling objects is performed by their visual distinction, any damage or degradation of

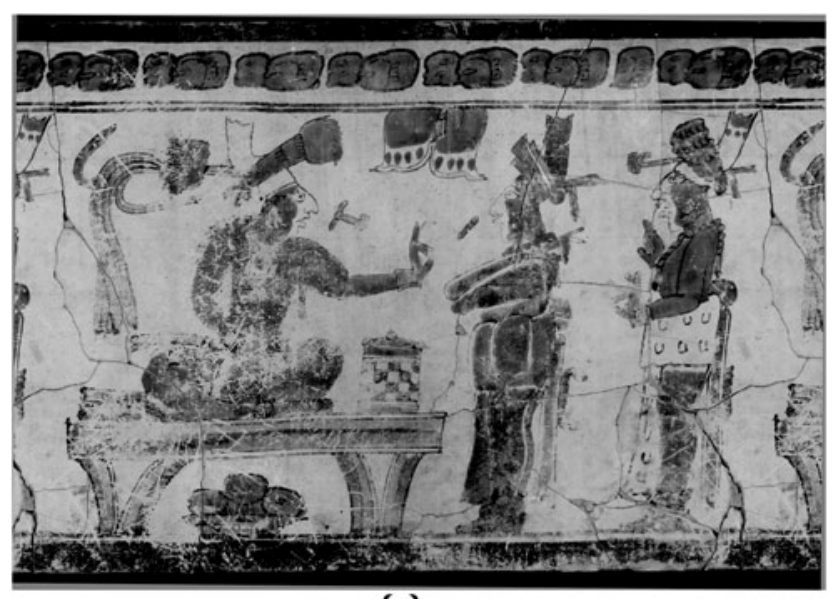

(a)

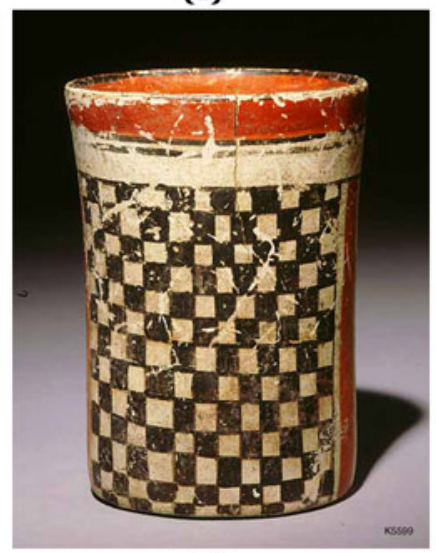

(b)

Figure 5. Image of decorated vessel by main figure (Kerr no. K5353) and example of same decoration (Kerr no. K5599). Photographs (C) Justin Kerr.

that visual distinction would subvert that intended and necessary function.

In the full corpus of known Maya iconography, royal accouterments are limited to: footwear, clothing, headdress, jewelry, back rack, staff, weapon, bench/throne, captives, tribute, food, and vessels. Cylinders are among the most commonly depicted vessels and, when present, they are depicted on or near the throne and in close proximity or in presentation to the main figure (typically the king). By its placement, the vessel is effectively a symbol of office or status. The socially and/or politically significant status obtained by the receipt and ownership of such a vessel (and/or its contents) has been widely demonstrated (see for example Adams 1971; Ball 1993; Houston et al. 1992; Kerr and Coe 1989-2000; LeCount 1999; Reents-Budet 2006; Reents-Budet et al. 1994, 2000; Stuart 2006; Tokovinine and Fialko 2007:361-362; Valdés 1997). In some cases, the presentation and acceptance of these vessels appears to be contractual (Ball 1993; Reents-Budet et al. 1994; Rice 2009; Rice and Rice 2009). Ownership granted a particular status, emblem of affiliation, and arguably associated rights, which may very well have included a permit for the consumption of a specific substance, or possibly be evidence of a claim to specific resources.

In the case of the cacao-labeled PSS cylinders, that resource would likely be the named cacao, the beans of which would be contained in the vessel. This might explain repaired vessels, where 
cracks were sown back together to preserve the symbol, yet an insufficient repair to contain a liquid. Repaired vessels or vessels bearing a parent's name transferred from the owner to another heir in the line of succession may have indicated an inheritance of such contract or permit. The handing over of such a powerful item might have been similar to the "investiture ceremonies at which particular privileges were transferred form [sic], or shared with, one closely-related individual to another" (Helmke 2010: 10). The owner of the vessel thereby has the privilege to have cacao available, presumably if the vessel is intact or the social contract exists. Not only were the cylinders never meant to hold liquid cacao, they were instead likely functioning as writs or deeds that held dried cacao beans.

If the PSS-labeled cylinders were not only a valued status item but also granted the owner stakes in cacao and/or its consumption, this may help explain middens where similarly decorated and labeled vessels were presumably used and immediately destroyed (e.g., Calakmul Structure 12). These middens may be evidence of events in which vessels were employed, status temporarily granted, then the permitting vessels taken out of circulation, no lasting symbol. "Through the provision of food and drink, hosts repay old social debts and create new ones" (Hendon 2003:205). Firth's (1983) model of "indebtedness engineering" suggests that social obligations can be as valuable as physical goods. Feasting creates a social event or "political-symbolic drama" (Cohen 1964), where the individuals involved are obligated to form or promote certain interests of the host within a highly symbolic set of social constraints (Dietler 1996:91). The consumption of goods during a feast immediately removes them from circulation. In some cases, durable goods are terminated at the conclusion of the event, thereby removing those objects from further circulation (Boas 1920; Codere 1950; Rathje 2002; Trigger 1990:124-128). The removal of goods from circulation, whether by destruction or consumption, serves to maintain or increase the value of the remaining objects. Presently, midden evaluation will remain as speculation until more evaluations of these deposits are conducted.

It is also possible that the statements in the PSS are directed at an imagined reader or listener who is in a situation where the cylinder vessel could be seen, read, and understood - both in the presence of the text and in the presence of the vessel (or vessels) to which the text refers. This is consistent with the widely-held view that these vessels may have been given out at large feasts (such as those described by Fray Diego de Landa Calderon in 1524; see Tozzer 1941:90) involving many members of the elite - both important individuals named on vessels made for them personally and others who are referred to only generically by their status. An abbreviated abstract of the PSS statement - that "N's drinking vessel for cacao is raised" (under the proposed reading $t$ ' $a b-i$, literally "it goes up"; Stuart 1995, 1998) - would be consistent with such a setting, among others. It may also be noted that, once given at such feasts, these messages could be appropriate on other occasions, such as in the homes of the owners of the individual vessels. If this is then the case, the PSS appears to be noting the participation and standing of the elite owners of these vessels who were attendees at major feasts, ritual, or rites.

The PSS remains formulaic when found on other vessel forms, monuments, clothing, and jewelry. "Remarkably, the same verbal constructions appear on a very wide-range of objects and monuments, and it seems quite clear that we are dealing with a highly formalized dedicatory formula used by scribes to mark the activation of precious things and monuments" (Stuart 2005:5). The alterations to the PSS text adjust for carving or painting, the object type inscribed, and the owner or artisan and titles. The rigid nature of this inscription suggests that the standardization must reflect a well-established and understood function. While the concepts of dedication, commemoration, and presentation are all semantically at play, they are under-specifying the purpose of the PSS text.

The PSS-labeled vessels, the substances, the depicted events, and ultimate terminal context are clearly ritual. The PSS is an active phrase and is applied to artifacts that are activated, as noted by Stuart (2005). For the Maya, ritual events regularly were cosmologically derived reenactments. Images of rituals suggest, and associated texts frequently indicate, that one or more elite individuals is channeling or acting "in the image of" a god. The foodstuffs present in these rituals, as depicted, are products associated with gods themselves, as known through the Madrid Codex, murals such as those at San Bartolo, and in vessel images. The PSS then, in part, could act as a sanctifying medium for the vessel, thereby activating the food and rendering it ritually consecrated, in other words, not just cacao but godly cacao.

Maize and cacao were of supreme cosmological importance in the origins of life and order, therefore under certain circumstances or ritual performances, consuming those foods would have been a reenactment of divine events. The mythological creation story told in the Popol Vuh describes how the creator gods formed humans from maize collected at the Mountain of Sustenance at Paxil Cayala, as well as the epic of the death and resurrection of the Maize God, and the actions of his sons The Hero Twins (Alcorn et al. 2006; Christenson 2004; Colop 1999; Sachse 2008; Sharer and Morley 1994; Stross 2006; Tedlock 1996; Townsend 2000). Scenes inspired by this epic are commonly depicted on the cylinders.

The Maize God (One Hunahpu) is at once both living maize and the food, as well as the origin of cacao. He is shown sprouting cacao pods from his body: "Classic Maya sources... give cacao a privileged position as the first or most prominent among the fruit tress grown from the Maize god's body" (Martin 2006:155, 163). The first cacao beverage was said to be produced by Hunahpu, the son of the Maize God (see Bourbourg 1858:499). Moreover, the severed head of the Maize God at one point in the story becomes part of the calabash tree in the underworld (Christenson 2004: 126). Calabashes (or bottle gourds) were commonly used as vessels, and were used as inspiration for later clay vessel forms. Tedlock (2002) described a wedding event where cacao was served to guests in gourd or clay bowls resembling gourds. These vessels were symbolically linked to the gourd skull of the Maize God: "[i]n other words, dear wedding guests, you are now drinking from the skull of the very person whose story we are telling" (Tedlock 2002:172).

The highly ornate and labeled cylinders were a powerful visual element. They were both a container and visible symbol related to some aspect of the foods of the gods, exclusive to the elites and ritually bound. There are likely numerous reasons why such cylinders could have been given, and their nature and association with these foods and cosmological events of supreme importance in Maya society suggest intent related to those associations behind their design. A durable symbol such as this was likely manipulated throughout its employment in the Late Classic according with changing trends, alliances, and ritual needs. The social importance of these associated foods and events, however, strongly suggests that the intent behind the creation and possession of these vessels should not be simply viewed in terms of mere food presentation vessels. 
MAYA VASES, ELITE RITUAL, AND ARTIFACT FUNCTION

Functional explanations should not be invertible - if A exists in order to promote $\mathrm{B}$, then $\mathrm{B}$ does not exist in order to promote A. This condition is motivated by some prime examples of functional explanation. In two of the most obvious cases where something exists because of its function - consciously designed artifacts and naturally selected traits - the explanations cannot be reversed. We have chairs in order to sit down but we do not sit in order to have chairs. (Kincaid 1990:343, emphasis added)

If, as the preceding discussion demonstrates, the elite cylinder vessels were not being used in the expected manner (i.e., holding liquid food products that are named in ostensibly labeling text or illustrated within a vessel's scenes), then the assumptions guiding our interpretation of the function of these vessels need to be reassessed. It is not sufficient to simply consider that if the vessels were not for common practical use that they could instead have been created as ritual or symbolic furnishings. This would merely be substituting an ascribed function for an assumed use. Instead, a robust interpretation needs to consider the intersection of both the object's actual use and the implications for its intended purpose and function. A vessel might be manufactured in the form of a cup but not necessarily intended to be used for containing and/or consuming a liquid or beverage. If a vessel were designed to look like a cup without the intention that it be used as one, then understanding its function may be contingent on its being understood not as a cup but as a representation of a cup. Moreover, representing (the idea of) a cup is only one possibility. The contents of the vessel have similar functional consequences.

For the cylinders, a possible explanation is that, through the naming or illustration of a substance, the vessel and foodstuff become emblematic of the event where they were used or consumed. In other words, the mere mention of the word kakaw or sakha' is heralding an event and implying the participants. The vessel is then serving as evidence or endorsement of potential participation and consumption at the event. If so, then the vessel and/or content is indicating the bearer's status, even if that vessel has never been "used." Tedlock (2002) has shown a similar act for wedding events, in which a decorated calabash harkens to the skull of One Hunahpu of the Popol Vuh and cacao contents (see also Vail 2009:6).

The above quote by Kincaid (1990) notes that a chair is an artifact made for sitting and not the cause of the sitting. In terms of a cup, the beverage is the content for drinking (we do not drink the cup), but the mere existence of a cup does not necessitate drinking. Likewise, cacao residue has been identified in a wide number of Maya vessels that are not labeled, are not cups, and are not necessarily cylindrical (e.g., Crown and Hurst 2009; Hall et al. 1990; Henderson et al. 2007; Hurst 2006; Hurst et al. 1989, 1998, 2002). Since certain cylinders weren't intended to be used for drinking, then what precisely is the "labeling text" indicating, and why is the vessel cup-shaped? The Mayas did drink cacao, and they usually drank it from small cups and bowls that did not have labeling text or images. Obviously, the label is not necessary for the drinking of cacao.

Cup and cup-like artifacts are extremely common, but proportionally few are labeled. Although the drinking of liquid cacao is an empirically supportable interpretation for some artifacts, it cannot necessarily be transferred to all formally similar artifacts merely on the basis of physical characteristics. The only conclusion we can reasonable make for vessels that do not contain residues of liquid cacao but are otherwise labeled with text is that the text, the artifact, and the cacao are related by independent aspects with intersecting performative functions. Re-conceptualizing the PSS as involving a reading or verbal performance, independent of the vessel itself, suggests that the PSS is evidence of a specific ritual performance. The indicated contents, whether seeds of cacao or maize kernels, are conceptually part of that performance - the consumption of them is, however, potentially independent of both the performed event and the indicating artifact.

We also, however, have images depicting foam or froth shown above the top of cylinder vessels, as well as images in which cylinders are held in such a manner to indicate that they could be holding a liquid readied for consumption. Although this may seem to conflict with the interpretations presented here, none of these images explicitly indicate that the depicted vessels are labeled, even though such decorations are explicitly and unequivocally indicated in other scenes (Figure 4). In addition, the middens in which many labeled vessels are recovered do indicate that, at times at least, some elite vessels may have been used in direct consumption practices, but this remains speculative, as no systematic residues analyses of these collections is available. These images may simply be illustrations of those acts of conspicuous consumption followed by vessel termination, or a depiction of a single act of consumption. Unfortunately, a lack of data leaves us unable to interpret these images with confidence at this time.

\section{Purpose, Use, Purpose, and Function of the created artifact}

The proper definition and conceptualization of artifact function has attracted some significant theoretical attention in archaeology and in philosophy of science (see Dennett 1990; Houkes and Meijers 2006; Kitamura and Mizoguchi 1999; Scheele 2006; Vaesen and van Amerongen 2008) due to the ambiguous ontological construction of the concept. The philosophical difficulty in such discussions is very explicitly illustrated by the case examined in this paper. Specifically, the function of an artifact relates not only to how the object was actually used, but also the combination of social contexts and intentions of both the maker and the user of the object. This ambiguity is concisely described by Houkes and Meijers (2006: 119), who note that:

\begin{abstract}
... artefacts have a 'dual nature' ... technical artefacts, that is, the products designed by engineers for practical purposes, are both physical bodies that have geometrical, physical, and chemical characteristics, and functional objects that have an intrinsic relation to mental states and intentional actions. This thesis can be developed in different directions, for example, conceptually, by connecting the two 'natures' in a coherent conceptualization (Kroes, 2006), or epistemically, by arguing that functional knowledge cannot be reduced to knowledge of physical characteristics (Houkes, 2006).
\end{abstract}

Although Houkes and Meijers are discussing the metaphysics of created objects (i.e., "artefacts") generally, the duality they identify is both particularly interesting and problematic in archaeological contexts, for which such intentions and contexts are the unknown subjects of interpretation. The intentions of both the maker of an object and its user(s) are unknowns. The archaeological use of the term function, therefore, can be somewhat vague in that it may variably refer to why an object was created, how it was used, the social context of its use, behavioral activities denoted by the object's presence or use, or some amalgamation of the above. Further, their 
second point, that function cannot be reduced to physical form, is especially pertinent to archaeological interpretation. It is essential for the following discussion, then, to distinguish between the specific connotations of the terms purpose, use, and function.

Any intentionally made object once served at least one purpose, which is its intended function and reason for its creation and/or curation. Artifacts can and often do serve multiple purposes throughout their life prior to eventual discard, termination, or abandonment. In this sense, purpose refers to the intentionality of the active behavioral agent in creating or utilizing said artifact, rather than an intrinsic characteristic of the object itself. This does not mean, however, that the artifact served any specific use in a customary utilitarian sense. Use in this connotation refers to the specific way that object was employed, which can be irrespective of its original or otherwise customary purpose. The actual use of an artifact is limited only by its physical capabilities, which is not necessarily constrained by prior intentions (e.g., a coffee mug or cup used to hold pencils; see Brooks 2005; Henrickson 1990; Rice 1987:139, 1989, 1996).

Function refers to the intersection of the intentionality of purpose and the enacted event of use. Interpretations of function require describing the full potential and capacity of an object both to fulfill a role or roles in the sense of both its objective use (e.g., a "cup-shaped vessel containing wine") and its contextual purpose (e.g., a "Communion chalice filled with a sacrament of the Eucharist"). Archaeologically, use can be determined through empirical evidence such as visible and identifiable remains or through some method of residue analysis whereas purpose must be inferred by contexts of use. Therefore, interpretations and any subsequent classifications of artifacts based on their function require both the contextual indications of purpose as well as an empirical assessment of use, each informed by the other.

Interpretation of purpose without specific evidence regarding use would be speculative, whereas description of use without the context of purpose only indicates action/event rather than behavior. Functional explanation in archaeology needs both the contextual and empirical data for artifacts and assemblages to enable such interpretations, or risks the inversion of functional explanation described by Kincaid (1990:343). Use simply describes, in the simplest physical sense, what is done with or to the object (e.g., an object that holds down loose papers). Purpose is wholly dependent on intention and contextual knowledge (e.g., a "paperweight"). Use and purpose are independent concepts that coincide only through the actions of a sentient agent enacting a use for a purpose, thereby initiating a function. An inanimate object obviously cannot have intent, so purpose is initially dependent on the object's maker and subsequently its user/consumer.

Conceptualization of function, therefore, cannot be established within one singular frame of reference. Any consideration of function must include an artifact's use and its purpose from the perspectives of both a social actor and either a real or a hypothetical observer within that social context. Function, then, is also closely related to behavior as social performance (Alexander 2004; Alexander and Smith 2001). The performance aspect of behavior that expresses the contextual purpose of an object's use is a matter of perception of purpose by the actor or ascribed intent by the observer. Once purpose is derived from the intentions of the social actor who is directly using the object or interacting with that object. Another purpose (or set of purposes), however, derives from the perspective of the observer(s) of the performance. Transmitter/actor and receiver/observer each have a contextual frame of reference for what is being communicated in the use of an object within those referential contexts. This relationship between communicator and receiver reinforces a dynamic interaction where symbolic referents are acknowledged and purpose is established contextually through intentional use.

This is where use and purpose overlap. Purpose speaks to motives that are not intrinsic to the object itself, and use is what actions are undertaken by a purposeful agent in utilizing the object. Since intent cannot be the property of a non-sentient object itself, purpose derives only from the mind of a human agent and the perceptions associated with the cultural contexts of the enactment of that purpose. An object, in and of itself, only has a use. An artifact as a piece of material culture has purposeful function only through the intents of the agent of its use, and those purposes are only extant in the minds and perceptions of the people around it. Artifact function related to purpose is thereby dependent on agent motives to determine both use and purpose contextually through actions. This renders both use and purpose independently dynamic aspects of function, and therefore these qualities depend on both actors and observers throughout the use-life of an object.

Although there are certain pragmatic constraints imposed by an object's design, nothing intrinsically ensures any specific intended use. As such, morphological form cannot be the sole or primary basis used to determine the function of vessels without substantial corroboration through other lines of evidence. Determination and/ or differentiation of such an artifact's intended or alternate uses, absent direct observation of use or naive reliance on morphological characteristics, requires an assessment of both observable evidence for use and the contextual parameters to ascertain purpose. Neither aspect alone is sufficient basis for a full functional interpretation, nor should one simply be presumed from the other, as each aspect is necessary.

Contemporary theoretical trends toward "symmetrical" approaches (e.g., Olsen 2007; Shanks 2007; Witmore 2007) attempt to address the dichotomy between utilitarian and symbolic aspects of material culture, citing the counter-productivity of segregating material versus social (or emic versus etic) interpretations. Olsen (2007:586) describes this inter-relationship of the material and the social, saying:

However far back we go into prehistory humans have extended their social relations to non-humans with whom they have swapped properties and formed collectives (Serres 1987:209; Latour 1999:198). If there is one historical trajectory running all the way down from Olduvai Gorge to Post-Modernia, it must be one of increasing materiality: more and more tasks are delegated to non-human actors, more and more actions mediated by things (Olsen 2003).

This, in certain superficial respects, is the approach promoted here, in that both the action of use and the intention of purpose are required to constitute and adequate interpretation of artifact function.

My approach diverges from the symmetrical approach, however, in other critical respects. I am primarily concerned with the intersection of multiple empirical and inferential lines of evidence (e.g., Wylie 1989) and their contribution to an understanding of the artifact's practical and social functions simultaneously. Although the emphasis here has been on reconciling the cylinders and their contexts with the empirical lack of residues, I do not agree with a complete social embedding of object and context as equivalent or 
indistinguishable entities sharing some abstract form of agency. In this, the parsing of function presented here shares more in common with pragmatics (e.g., Preucel 2016; Preucel and Bauer 2001) as approached from the empirical (rather than semiotic) direction, which was necessitated by the seemingly contradictory information presented by residues analysis, archaeological classification of artifacts, and epigraphy or iconography.

Material and quantitative empirical analyses can address both use (in the mundane, pragmatic sense) and purpose (in the contextual, constructivist sense), but only by dispensing with: (1) categorical classificatory systems derived from mono-functional ascriptions based on form; (2) functional a priori templates derived from modern classificatory assignments; and (3) overreliance on textual/iconographic literality. Social sciences have largely moved away from functionalist explanations of behavior, but certain basic assumptions of functional explanation have remained intrinsic to material studies (e.g., discussions in Brooks 2005; Dennett 1990; Houkes 2006; Houkes and Meijers 2006). Functional categorization of artifacts, based on presumptive use, typically form the basis of assemblage pattern analyses. Artifact functions are used as proxy for behavioral activities to describe broader patterns within artifact assemblages that might indicate behavioral contexts.

\section{Functional Classification and Maya Vessels}

The parsing of the concept of function presented above, as it pertains to the traditional classifications of Maya vessels, can clarify how ascribed functional categorizations tend to invert the proper order of functional explanation as specified by Kincaid (1990). Specifically, the classification of vessels based on formal characteristics inadvertently presupposes function by applying an overly restrictive conceptualization of function and a typological schema that conflates form and use. The overriding problem addressed in this paper is that elite vessels have largely been categorized based on form, which is thereby implying or assuming a function. The problem of such ascribed function based on formal or physical characteristics is most clearly characterized by Houkes (2006:107):

\footnotetext{
The question is rather what is its [the artifact's] proper function? Neither observation of physical characteristics nor current use know-how provide sufficient evidence to settle this question: intuitively, we need to know how the item was used originally or what it was originally designed for... Hence, unless the person ascribing a proper function to an artefact is its creator, he needs to go beyond his personal experience and knowledge to acquire knowledge of the function. This knowledge, in other words, has a social back- ground: with proper functions, we enter the somewhat murky waters of social epistemology.
}

This passage succinctly identifies a critical problem for functional artifact classifications in archaeology in general. The tautological classification schema created by assumed functions leads us nowhere but where we expected to go. In the case of the Maya vessels discussed here, the standard classification and interpretation of the cylinders has largely erred on both counts identified by Houkes. By using the formal similarities to ethnographic or ethnoarchaeological samples, as well as subsequent ascription of function based on a presumption of literality for the text and images, the proper and intended function(s) of the cylinders was obscured from the outset.

Presuming a vessel to have performed a particular task due only to its form excludes the social actor(s) from consideration. The key aspect of Kincaid's functional explanation, as it pertains to the explanation of artifacts, is that purpose ("sitting") precedes object ("chair") such that the order of purpose and object cannot rationally be inverted (e.g., ascribed classifications) or conflated (e.g., the symmetrical premise). Purpose and object must be kept distinct logical entities, regardless of how related. In this case, the formal classifications of a "chocolate pot" or a "tamale plate" presume an explicit use by the nominal modifiers (i.e., "chocolate" or "tamale"), which then impose function as well as use for such vessels. This tautologically establishes an a priori interpretation, based on formal characteristics, through the interpretive categorical assertion. Form may facilitate or constrain specific uses, but function depends on the extrinsic aspect purpose as well.

This is particularly pertinent in the case of sumptuary vessels, which were likely not intended to be used in the same manner as their utilitarian or domestic formal counterparts. Following from prior discussion of functional explanation, a vessel can be manufactured with the intention that it function as a cup, but never actually be used as a drinking vessel (e.g., a shot glass kept as a souvenir or filled with a dessert). Conversely, a vessel could have been designed in the form of a cup but not intended to be used as one (e.g., a trophy, commemorative glass, or other such curio objects). Therefore, if a vessel were designed to look like a cup but not to be used as one, then its intended purpose and subsequent function may, instead, be contingent on its understood representation as a cup to symbolize or elicit some other recognition. In such a case, it would still have an intended purpose for participating in a nonutilitarian or alternate activity and therefore have both a use and a purpose (i.e., function), but not necessarily just the expected functions from the common (or out of context) cues from its morphological attributes.

This is not to say, however, that expectations of function and use should not be kept practical, taking into account physical and morphological characteristics, but only that those should not be the sole consideration. Indeed, archaeologists have identified vessels and artifacts consistent with beverage production (see LoughmillerCardinal 2018), and confirmed their intended use from murals and other images on the cylinders. The large ollas, for example, are ideal production vessels for alcoholic beverages. Manos and metates are appropriate for grinding corn and cacao beans. The small bowls and cups are readily suitable for drinking. It cannot necessarily, however, reasonably be assumed that these vessels were concurrently used for preparation, service, and consumption, especially in the case of sumptuary goods.

At this time, it has not been determined what the complete assemblages, specific vessels, and associated paraphernalia used in ancient Maya practices and production for any given ritual or formal event. Feasts and other events that include the consumption of foods from the vessels, rather than offerings to the deities or as accompaniment to the deceased, suggest that specific forms would be needed to accommodate the containment of the foodstuffs. On the contrary, what we know from actual elite artifact assemblages recovered during excavation (specifically burial goods) does not cleanly follow with the needs of an individual to imbibe and consume. Either there is an overrepresentation of a certain vessel form, or there is insufficient gear to accommodate consumption needs. Instead, what we find bears little resemblance to the expected assemblage of feasting paraphernalia for a single person. We must instead consider the vessels and archaeological context as evidence of the vessels' intended use, and ultimately their actual function, and not merely as objects representative of a single ritual deposit or performative task. 
Another matter of concern is that elite vessels are habitually viewed simply as the "fancy" version of their utilitarian counterparts. The presumption that elite wares are simply formal variations or domestic goods is flawed from the onset. This sets up a presumptive and tenuous domestic/elite dichotomy that elite goods were produced merely as elevated status counterparts to domestic utilitarian wears. Some of the elegantly designed vessels may indeed be the "good china," but others show little evidence of wear or have construction and/or decoration that make their practical utility unlikely. In the latter case, their impracticality strongly suggests that their purpose is one of far greater significance than as a fancy version of a serving vessel or container. In addition, presence of text and/or image suggesting specific contents of a vessel or form of vessel further complicates gross categorizations from formal characteristics. The assumption operating here is that, because an image of a food item or a vessel form is illustrated or, more commonly, that a word for a food product is present, then the immediate logical conclusion is that it is a label.

Judging by the archaeological contexts in which they are found and the elaborate treatment and curatorial care, it seems apparent that these vessels are not just fancy dinnerware and their text not simply a label. It seems to be stretching the bounds of credulity to evaluate them as elite-associated but otherwise functional equivalents of utilitarian vessels. These more elaborate treatments would suggest that these objects had significance in and of themselves. Again, this illustrates the inadequacy of basing functional categories on use-forms alone. We must therefore greatly expand the conceptualization of function beyond an object's use. Only by incorporating both use and purpose within this expanded view of function can we fully establish the interpretive utility of these vessels and their role in the ritual performances of Maya elites.

\section{CONCLUSIONS AND SUMMARY}

The hieroglyphically labeled cylindrical Maya "chocolate" vessels do not appear to have been intended for holding or imbibing liquid cacao, but instead were likely used for presenting and storing dried cacao beans or perhaps seeds. This is not to say that cylinders never held liquid or were never used for drinking, rather that the evidence for such uses is not present. That none of the cylinders discussed here contain such evidence makes it doubtful that those uses were common practices. The use, function, and purpose all need to be separated in order to fully appreciate the vessel. The presentation of a highly decorated and textually embellished cylindrical vessel was itself a means of visually providing a symbol of affiliation. Owning such a vessel was emblematic of status as well as denoting participation in some political relationship, ritual, or significant event. The text and image provide clues to what those events might have been, the color and style suggest the affiliate. The text and image also highlight the importance of food and drink in high ritual contexts, especially cacao and maize.

Both maize and cacao are supremely important foodstuffs among the Maya, both symbolic of the gods as well as food that is god (at least some aspect). This is set amongst mythology of the Popol Vuh and the epic tale of the Maize God and his sons as well as the ritual significance of food. The lack of residues noted here, in addition to the research conducted by other researchers on similar vessels, leaves little doubt that processed cacao or cacao beverages were not consumed from these vessels. The design and the limited durability of the thin, elegant cylinders are not sufficient to carry heavy, staining liquids. Interior wear is inconsistent with liquid contaminant. Due to the porous body and surface treatment, limited duration or even single-use of the vessels for consuming a cacao beverage would have left detectable residue in at least one of the vessels tested here or by others.

The lack of residues considered with the designs and sizes of the decorated and labeled cylinders and instances of their post-repair curation and interment, suggests that direct consumption of a liquid beverage from the vessel was neither practiced nor intended. The use-wear that does occur on some of these vessels, in the form of vertical striations or abrasions, is consistent with the containment and removal of dried contents that would also leave no absorbed or readily detectable residues. Since the construction and empirical use of these vessels demonstrates an intended purpose for something other than the consumption of a cacao beverage, then the purpose of texts on these vessels indicating both "cacao" (kakaw) and "drinking" ('uk'iib') need to be readdressed with respect to dry contents rather than a liquid.

References to kakaw in the labeling PSS text are either unmodified or modified by an indication of a variety, source, or additive. It is less clear, however, that such references must be specifically indicating a beverage form. It is largely the additional presence of ' $u k$ 'iib' and the vase-like form of the vessels that have promoted the connotation of beverage, with the assumption that the text is referring to or dedicating the vessel itself or its use as a drinking vessel. The vessels were not used for direct consumption, so the PSS would not be in reference to the labeled vessel. If the function of the PSS labeling is a reference or dedication to either the contents of the vessel or the drinking of a beverage with those contents as an ingredient, then the apparent contradiction that the vessels were not in fact used or intended for drinking or containing a liquid beverage is resolved. By referring to the contents instead of the vessel, the PSS can still dedicate or sanctify either a beverage to be consumed that is subsequently made from the contents contained within the vessel, or allowed to be consumed through the possession of that content or vessel.

This interpretation is not at all contradicted by the confirmed presence of residues in the Rio Azul vessel, but rather supported by that find. The Rio Azul vessel did, at some point, contain cacao in a form that left residues (i.e., either liquid or pulped) and does bear the labeling text of kakaw and 'uk'iib', but is quite clearly a storage container and not a drinking vessel. In that case, as well as in the cases described here in which no such content was found, the reference and dedication by the PSS of the contents of the vessel for use in consumption of a beverage (i.e., from some other vessel more practicable for drinking) clarifies the seeming contradiction between text and object.

The full contextual purpose of the PSS remains opaque. The revelation that the text, as it occurs on the "chocolate" vases, is not necessarily addressing the medium on which it appears or the specific form of the contents (i.e., a liquid beverage in this case) allows for broader reconsideration of its purposes. Previous interpretations of the PSS in this context have been limited by the expectation that functional or folk classification of the vessels as drinking vessels matched the literal reading for ' $y$ ' $u k$ ' $i i b$ ', "his/hers/its for drinking." Those assumptions have now been proven empirically unfounded. Indications that the text was likely speaking of dried seed content have been suggested before (MacLeod 1990; also Lacadena [personal communication 2005] in Beliaev et al. 2010: 258), or contents generally (John Justeson, personal communication 2017), but until now that seemed to be unlikely given the apparent contradiction imposed by the presumption that its reference to drinking was referring to the labeled object itself. With the empirical confirmation that the contents of the vessels could not have been a 
liquid beverage and a shifting of the PSS referents to content rather than vessel, those limitations and contradictions are removed.

Recognizing that the vases likely held dried seed contents and that the PSS is therefore actively addressing the content rather than then the vessel itself, then interpretations of the functional role of both the vessel and the text are far less hindered. Moreover, through the broadened theoretical construct of function presented here, the dual functional aspects of both use and purpose for the PSS can be informed through these empirical findings. Specifically, the vessel was not used for containing liquid cacao or as a drinking vessel, and the use of the PSS was not to dedicate or sanctify the vessel for doing so. Instead, the vessel was used to present either dry content of kakaw or otherwise to signal that the owner/possessor of the vessel was permitted access to it and the PSS labeling used to sanctify or authorize that use as ritually correct. These data thereby narrow the possible range of potential purposes for both vessel and PSS.

Although the movement, gifting, and presentation of cylinders have been well-described (Ball and Brotherson 1992; Giardino et al. 1998; Houston 2004; Inomata and Houston 2001; Miller et al. 2004; McNeil 2010; Reents-Budet et al. 1994) there may be an otherwise unrecognized contractual or permitting aspects of the gift. The elaborate decoration of these cylinder vases, and the exaggerated proportions and/or unusual forms of some of them, strongly indicates that these vessels are intended to be visually distinct and recognizable. The presence of the formulaic PSS text labeling and the inclusion of these distinctive vessels in elite iconography signify their symbolic and ritual connotation as accouterments of elite status. Following from the interpretation argued here that the PSS and vessel are both means of reference to the vessel contents, then the movement, gifting, and presentation of the cylinders would in essence be a correlative and symbolic reference to the use and consumption of kakaw as the indication and authorization of that status. Therefore, the conferment of rights to kakaw, through presentation of the indicative vessel and contents, would function as the socially recognized and ritually sanctioned conferment and/or affirmation of elite status.

As noted earlier, many of these vessels are found in burial contexts and some were found to have been repaired. If the vessels are indeed indicators of conferred status, then their contexts and curation further distinguishes them as sumptuary goods with significance outside elite but utilitarian uses. Although it is proposed here that the vessel's content is the primary referent of the vessel and text, the vessel itself has significant function and importance as the medium through which the conferred status is communicated and symbolized. The repair and curation of these objects beyond viable utilitarian use indicates that the fact of a specific vessel (rather than merely the class of vessel) was significant in and of itself, to be maintained and ultimately interred with its individual possessor. This has implication that object and owner were uniquely related subsequent to the vessel's receipt. In other contexts, such as similar vessels found in midden deposits, such owner/ object relationship may have been severed following a particular event reflecting a temporary conferment of right (e.g., consumption of ritual content) or status (e.g., event participant).

In the case of both the vessels and the PSS text, the purpose and function of the artifact have been obscured by an ascribed use that would logically follow from the formal or functional classification. Through the overly literal translation of ' $u$ ' 'iib' and vessel classification based on vessel form and ethnographic analogy, the use of the vessels was assumed to be for drinking or the direct consumption of a beverage. This demonstrates the limitation of such systems of classification and their potentially negative affect on interpretation. A more reasonable understanding and interpretation of artifact function is allowed through empirically ascertained determinations of use and subsequent inference of purpose. In the case of the Maya cylindrical vessels, the ostensible use attributed through the functional or folk classification has obscured the function and uses of both the vessels themselves and the PSS text. Exploring specific parameters of use through empirical means permits a much more robust combination of empirical and inferential interpretation.

The data presented in this paper are informed by multiple lines of evidence that can be confirmed directly and empirically or through inference from external empirical sources. The conclusions are derived from more robust theoretical constructs of use and purpose that define them as contributing elements to the compound concept of function. These definitions are reinforced by recognition that use and purpose do not follow from form and function in the way that functional and folk classification has previously been applied. Evidence from linguistics, epigraphy, iconography, and archaeological context combine with the chemical residue analyses to establish the limiting parameters of potential use from which the limits of purpose can be inferred. By also utilizing multiple lines of evidence to inform inferential interpretation, new conclusions can be drawn from the existing body of literature and data. When considered separately, each of these lines of evidence have resulted in either inconclusive or incorrect inferences that have obscured the interpretation of this class of vessels and their broader behavioral and cultural contexts. When combined, however, not only can they cross-validate or refute the findings of each but also provide entirely new avenues of insight.

\section{RESUMEN}

A través del tiempo, los vasos o copas han sido considerados la vasija principal para el consumo de bebidas, sin considerar toda la variedad de artefactos que existen no solamente para su consumo, sino para su producción, preparación y servicio; por el contrario no todos los contenedores con forma de taza estaban diseñados para ser utilizados como recipientes para beber o para contener líquidos. Para el periodo clásico maya (250-900 d.C.) las vasijas cilíndricas decoradas en particular, esta investigación demuestra que los residuos de sus contenidos no concuerdan con los contenidos y usos que los epigrafistas han interpretado. La disparidad entre las expectativas y los datos indican que hemos mal interpretado no solamente las vasijas y el texto, sino que además pudimos haber pasado por alto uno o más tipos de vasijas. La presente investigación sugiere una re evaluación de la idea de que todos los artefactos cilíndricos tenían como función servir para el consumo de líquidos, y que aquellos a los que actualmente nos referimos como vasos chocolateros, nunca fueron usados para tal propósito, sino para el almacenamiento u obsequio de granos de cacao, que ayudarían a evitar el desperdicio o la pérdida de los mismos. También le permitían al dueño consumir el cacao mezclado con cualquier tipo de líquido de un recipiente menos valioso, como aquellos en los que se han encontrado rastros de cacao a través de los análisis químicos y biológicos y que han sido identificados en representaciones antiguas de bebidas. Estos resultados nos darán un nuevo contexto para interpretar los usos, 
funciones y propósitos de estas vasijas. Los métodos extraídos de las ciencias naturales y sociales se utilizan para relacionar los materiales arqueológicos, los residuos de sus contenidos antiguos, sus textos jeroglíficos, la iconografía y su uso en la antigüedad. Esta diversidad de métodos acentúa que la combinación de datos de todas estas fuentes restringe las interpretaciones de cada una de ellas, y muestra que nuestras expectativas iniciales sobre los vasos con etiquetas jeroglíficas han sido demasiado específicas. La determinación de las funciones y los usos de estos buques no es tan simple como hemos estado suponiendo, pero las diferencias relevantes entre ellas, nos dan acceso a sistemas más complejos de prácticas culturales.

\section{ACKNOWLEDGMENTS}

The author most sincerely thanks the numerous individuals, institutions, and agencies that have helped with this research over these past years. I deeply appreciate the time and consideration of the many extraordinary scholars and minds who offered suggestions, considerations, and improvements to this research. I especially thank J. Scott Cardinal, Dmitri Zagorevski, John Justeson, Ignacio Casas, Ramon Carrasco, Veronica Vazquez-Lopez,

\section{REFERENCES}

Adams, Richard E. W., and Frank P. Saul

1971 The Ceramics of Altar de Sacrificios. Harvard University Press, Cambridge.

Alcorn, Janis B., Barbara Edmonson, and Candido Hernandez Vidales

2006 Thipaak and the Origins of Maize in Northern Mesoamerica. In Histories of Maize: Multidisciplinary Approaches to the Prehistory, Linguistics, Biogeography, Domestication, and Evolution of Maize, edited by John E. Staller, Robert H. Tykot, and Bruce F. Benz, pp. 600-608. Elsevier Academic Press, Boston.

Alexander, Jeffery C.

2004 Cultural Pragmatics: Social Performance Between Ritual and Strategy. Sociological Theory 22:527-573.

Alexander, Jeffery C., and Philip Smith

2001 The Strong Program In Cultural Theory: Elements of a Structural Hermeneutics. In Handbook of Sociological Theory, edited by J. H. Turner, pp. 135-150. Handbooks of Sociology and Social Research, Part II. Springer, New York.

Aulie, H. Wilber, and Evelyn W. de Aulie

1978 Diccionario ch'ol-español, español-ch'ol. 1st ed. Vocabularios Indígenas 21. Instituto Lingüístico de Verano, Mexico City.

Ball, Joseph W.

1993 Pottery, Potters, Palaces and Polities: Some Socioeconomic and Political Implications of Late Classic Maya Ceramic Industries. In Lowland Maya Civilization in the Eighth Century AD, edited by J. Sabloff and J. Henderson, pp. 243-272. Dumbarton Oaks Research Library and Collection, Washington, DC

Ball, T. B., and J. D. Brotherson

1992 The Effect of Varying Environmental Conditions on Phytolith Morphometries in Two Species of Grass (Bouteloua curttipendula and Panicum vigatum). Scanning Microscopy 6:1163-1181.

Battcock, Mike, and Sue Azam-Ali

1998 Fermented Fruits And Vegetables: A Global Perspective. FAO Agricultural Services Bulletin No. 134. Food and Agriculture Organization of the United Nations, Rome.

Beliaev, Dmitri, Albert Davletshin, and Alexandre Tokovinine

2010 Sweet Cacao and Sour Atole: Mixed Drinks on Classic Maya Ceramic Vases. In Pre-Columbian Foodways: Interdisciplinary Approaches to Food, Culture, and Markets in Ancient Mesoamerica, edited by J. E. Staller and M. D. Carrasco, pp. 257-272. Springer, New York.

Boas, Franz

1920 The Social Organization of the Kwakiutl. American Anthropologist 22:111-126.

Boot, Erik

1997 Classic Maya Vessel Classicfication: Rare Vessel Type Collocations Containing the Noun Cheb "Quill." Estudios de Historia Social y Economica de America 15:59-76.

2003 A New Classic Maya Vessel Type Collocation on a Uaxactun-style Plate. Electronic document, http://www.mayavase.com/bootplate.pdf (accessed August 2010).

2005 A Preliminary Overview of Common and Uncommon Classic Maya
Omar Rodriguez, Peter Biro, David Mora-Marín, Marty Pickands, Justin Kerr, Dicey Taylor, Christophe Helmke, Carlos Pallan, David Stuart, Terrance Kaufman, Peter Matthews, Erik Boot, Dmitri Beliaev, Nicholas Carter, Jean Loughmiller, and James Cardinal. A special note of thanks I extend to Amalia Perez Rodriguez. I also express my gratitude for the considered and attentive comments provided by the reviewers of this paper.
Vessel Type Collocations in the Primary Standard Sequence. Electronic document, www.mayavase.com/BootVesselTypes.pdf (accessed June 2008).

Bourbourg, Brasseur de

1858 Histoire des nations civilisées du Mexique et de l'AmériqueCentrale, durant les siècles antérieurs à Christophe Colomb. Vol. 4. A. Bertarand, Paris.

Bronson, Juan, Andrew Miller, Marta Estrada, and Kyle Meister

2014 Growing Pataxte. Electronic entry, https://impactforestry.org/ 2014/06/02/growing-pataxte/ (accessed September 2015).

Brooks, Alasdair

2005 Observing Formalities - The Use of Functional Artefact Categories in Australian Historical Archaeology. Australasian Historical Archaeology 23:7-14.

Charters, S., R. P. Evershed, L. J. Goad, P. W. Blinkhorn, and V. Denham 1993 Quantification and Distribution of Lipid in Archaeological Ceramics: Implications for Sampling Potsherds for Organic Residue Analysis. Archaeometry 35:211-223.

Christenson, Alan J.

2004 Popol Vuh: Literal Poetic Version. University of Oklahoma Press, Norman.

Ciudad Real, Antonio de

1984 Calepino maya de Motul. Universidad Nacional Autonoma de Mexico and Instituto de Investigaciones Filologica, Mexico City.

Codere, Helen F.

1950 Fighting with Property: A Study of Kwakiutl Potlatching and Warfare, 1792-1930. American Ethnological Society, Monograph 18. University of Washington Press, Seattle.

Coe, Michael D.

1973 The Maya Scribe and His World. Grolier Club, New York.

Coe, Michael D., and Justin Kerr

1998 The Art of the Maya Scribe. Harry N. Abrams, New York.

Coe, Sophie D., Michael D. Coe, and R. J. Huxtable

1996 The True History Of Chocolate. Thames and Hudson, London.

Cohen, Yehudi A.

1964 The Establishment of Identity in a Social Nexus: The Special Case of Initiation Ceremonies and Their Relation to Value and Legal Systems. American Anthropologist 66:529-552.

Colas, Piere R., Christophe Helmke, Jamie Awe, and Terry Powis

2002 Epigraphic and Ceramic Analyses of Two Early Classic Maya Vessels from Baking Pot, Belize. Mexicon 2:33-39.

Colop, Samual L.E (translator)

1999 Popol Wuj. Colecciacuteon Biblioteca Guatemala, F and G Editores, Guatemala City.

Crown, Patricia L., and Jeffery W. Hurst

2009 Evidence of Cacao Use in the Prehispanic American Southwest. Proceedings of the National Academy of Sciences of the United States of America 106:2110-2113.

Dennett, Daniel C.

1990 The Interpretation of Texts, People and Other Artifacts. Philosophy and Phenomenological Research 50:177-194. 
Dietler, Michael

1996 Feasts And Commensal Politics in the Political Economy: Food, Power, and Status in Prehistoric Europe. In Food and the Status Quest: An Interdisciplinary Perspective, edited by P. W. Wiessner and W. Schiefenhövel, pp. 87-125. Berghahn Books, Providence.

Evershed, Richard P.

2008 Experimental Approaches to the Interpretation of Absorbed Organic Residues in Archaeological Ceramics. World Archaeology 40:26-47.

Firth, Raymond

1983 Magnitudes and Values in Kula Exchange. In The Kula: New Perspectives on Massim Exchange, edited by J. W. Leach and E. Leach, pp. 89-102. Cambridge University Press, Cambridge.

Giardino, Marco, Richard Miller, Rachel Kuzio, and Dean Muirhead

1998 Analysis of Ceramic Color by Spectral Reflectance. American Antiquity 63:477-483.

Green, Judith Strupp

2010 Feasting with Foam: Ceremonial Drinks of Cacao, Maize, and Pataxte Cacao. In Pre-Columbian Foodways: Interdisciplinary Approaches to Food, Culture, and Markets in Ancient Mesoamerica, edited by John E. Staller and Michael D. Carrasco, pp. 257-272. Springer, New York.

Grube, Nikolai

1986 An Investigation of the Primary Standard Sequence on Classic Maya Ceramics. Sixth Palenque Round Table 8:223-232.

1990 The Primary Standard Sequence on Chochola Style Ceramics. In The Maya Vase Book: A Corpus of Rollout Photographs of Maya Vases, Vol. 2, edited by Justin Kerr and Michael D. Coe, pp. 320-330. Kerr Associates, New York.

Hall, Grant D., Stanley M. Tarka Jr., W. Jeffery Hurst, David Stuart, and

Richard E. W. Adams

1990 Cacao Residues in Ancient Maya Vessels from Rio Azul, Guatemala. American Antiquity 55:138-143.

Hellmuth, Nicholas M.

2010 Introduction to the Pataxte Form of Cacao in Mayan Ethnobotany Theobroma bicolor: Guatemala, Mexico, and Belize. Foundation for Latin American Anthropological Research (FLAAR). Electronic document, https://www.maya-archaeology.org/Mayan_anthropology_ethnography_ archaeology_art_history_iconography_epigraphy_ethnobotany/pataxte_ pataste_pataschte_Belize_Mexico_Guatemala_Honduras_sacred_flowers_ fruits_religion_cacao_chocolate_Theobroma_bicolor_balamte_jaguar_ tree.php (accessed February 2012)

Helmke, Christophe

2010 The Transferral and Inheritance of Ritual Privileges: A Classic Maya Case from Yaxchilan, Mexico. Wayeb Notes 35:1-14.

Henderson, John S., and Rosemary A. Joyce

2006 Brewing Distinction: The Development of Cacao Beverages in Formative Mesoamerica. In Chocolate in Mesoamerica: A Cultural History of Cacao, edited by Cameron L. McNeil, pp. 18937-18940. University Press of Florida, Gainesville.

Henderson, John S., Rosemary A. Joyce, Grant R. Hall, W. Jeffery Hurst, and Patrick E. McGovern

2007 Chemical and Archaeological Evidence for the Earliest Cacao Beverages. Proceedings of the National Academy of Sciences of the United States of America 104:18937-18940.

Hendon, John A.

2003 Feasting at Home: Community and House Solidarity among the Maya of Southeastern Mesoamerica. In The Archaeology and Politics of Food and Feasting in Early States and Empires, edited by Tamara L. Bray, pp. 203-233. Springer, New York.

Henrickson, Eric F.

1990 Investigating Ancient Ceramic Form and Use: Progress Report and Case Study. In The Changing Roles of Ceramics in Society: 26,000 B.P. to the Present, Vol. 5, edited by W. D. Kingery, pp. 83-117. American Ceramic Society, Westerville.

Houkes, Wybo

2006 Knowledge of Artefact Functions. Studies in History and Philosophy of Science Part A 37:102-113.

Houkes, Wybo, and Anthonie Meijers

2006 The Ontology of Artefacts: The Hard Problem. Studies in History and Philosophy of Science Part A 37:118-131.

Houston, Stephen D.

1989 Maya Glyphs (Reading the Past). University of California Press and British Museum, Berkeley and London.
2004 The Archaeology of Communication Technologies. Annual Review of Archaeology 33:233-250.

Houston, Stephen D., David Stuart, and Karl Taube

1987 "Name Tagging" in Classic Mayan Script: Implications for Native Classifications of Ceramics and Jade Ornaments. Mexicon 9:38-41.

1989 Folk Classification of Classic Maya Pottery. American Anthropologist 91:720-726.

1992 Image and Text on the "Jauncy Vase." In The Maya Vase Book, Vol. 3: A Corpus of Rollout Photographs of Maya Vases, edited by Justin Kerr, pp. 498-512. Kerr Associates, New York.

Hull, Kerry

2010 An Epigraphic Analysis of Classic-Period Maya Foodstuffs In Pre-Columbian Foodways: Interdisciplinary Approaches to Food, Culture, and Markets in Ancient Mesoamerica, edited by John E. Staller and Michael Carrasco, pp. 235-256. Springer, New York.

Hurst, W. Jeffery

2006 The Determination of Cacao in Samples of Archaeological Interest. In Chocolate in Mesoamerica: A Cultural History of Cacao, edited by Cameron L. McNeil, pp. 105-116. University Press of Florida, Tallahassee.

Hurst, W. Jeffery, R. A. J. Martin, Stanley M. Tarka Jr., and Grant D. Hall 1989 Authentication of Cocoa in Ancient Mayan Vessels Using HPLC Techniques. Journal of Chromatography 446:279-289.

Hurst, W. Jeffery, Stanley M. Tarka, Jr. and K. L. Prufer 1998 The CE determination of Caffeine and Theobromine in Samples of Archaeological Interest. Paper presented at PittCon 98, New Orleans.

Hurst, W. Jeffery, Stanley M. Tarka Jr., Terry Powis, Fred Valdez Jr., and Thomas R. Hester

2002 Archaeology: Cacao Usage By the Earliest Maya Civilization. Nature 418:289-290.

Inomata, Takeshi, and Stephen Houston

2001 Royal Courts of the Ancient Maya. 2 vols. Westview Press, Boulder.

Joyce, Rosemary A., and John S. Henderson

2007 From Feasting to Cuisine: Implications of Archaeological Research in an Early Honduran Village. American Anthropologist 109:642-653.

Kaufman, Terrence, and John Justeson

2003 A Preliminary Mayan Etymological Dictionary. Electronic document, http://www.famsi.org/reports/01051/index.html (accessed January 2010).

Kaufman, Terrence and John Justeson

2006 The History of the Word for 'Cacao' and Related Terms in Ancient Meso-America. In Chocolate in Mesoamerica: A Cultural History of Cacao, edited by Cameron L. McNeil, p. xvi. University Press of Florida, Gainesville.

2007 The History of the Word for Cacao in Ancient Mesoamerica. Ancient Mesoamerica 18:193-237.

2009 Historical Linguistics and Pre-Columbian Mesoamerica. Ancient Mesoamerica 20:221-231.

Kerr, Justin, and Michael D. Coe (editors)

1989-2000 The Maya Vase Book: A Corpus of Rollout Photographs of Maya Vases. 6 vols. Kerr Associates, New York.

Kew Science

2017 Theobroma cacao. Electronic document, http://powo.science.kew. org/taxon/urn:1sid:ipni.org:names:320783-2 (accessed October 2017).

Kincaid, Harold

1990 Assessing Functional Explanation in the Social Sciences. PSA: Proceedings of the Biennial Meeting of the Philosophy of Science Association 1:341-354.

Kitamura, Yoshinobu, and Riichiro Mizoguchi

1999 Meta-Functions of Artifacts. Proceedings of the Thirteenth International Workshop on Qualitative Reasoning (QR-99):136-145.

Kufer, Johanna, and Cameron L. McNeil

2006 The Jaguar Tree (Theobroma bicolor Bonpl.). In Chocolate in Mesoamerica: A Cultural History of Cacao, edited by Cameron L. McNeil, pp. 90-104. University Press of Florida, Gainesville.

Latour, Bruno

1999 Pandora's Hope. Essays on the Reality of Science Studies. Harvard University Press, London and Cambridge, MA.

Laughlin, Robert M.

1975 The Great Tzotzil Dictionary of San Lorenzo Zinacantan. Smithsonian Contributions to Anthropology, No. 19. Smithsonian Institution Press, Washington, DC. 
LeCount, Lisa J.

1999 Polychrome Pottery and Political Strategies in Late and Terminal Classic Lowland Maya Society. Latin American Antiquity 10:239-258.

Loughmiller-Cardinal, Jennifer A.

2018 Mayan Ritual Beverage Production: Considering the Ceramic. In Ancient Psychoactive Substances, edited by Scott M. Fitzpatrick, pp. 198-233. University of Florida Press, Gainesville.

Loughmiller-Cardinal, Jennifer A., and Dmitri V. Zagorevski

2016 Mayan Flasks: The "Home" of Tobacco and Godly Substances. Ancient Mesoamerica 27:1-11.

Loughmiller-Newman, Jennifer A

2008 Canons of Maya Painting. Ancient Mesoamerica 19:29-42.

2012 The Analytic Reconciliation of Classic Mayan Elite Pottery: Squaring Pottery Function with Form, Adornment, and Residual Contents. Ph.D. dissertation, Department of Anthropology, State University of New York, Albany.

MacLeod, Barbara

1990 Deciphering the Primary Standard Sequence. Unpublished Ph.D. dissertation, Department of Anthropology, University of Texas, Austin.

McNeil, Cameron L.

2006 Traditional Cacao Use in Modern Meosamerica. In Chocolate In Mesoamerica: A Cultural History of Cacao, edited by Cameron L. McNeil, pp. 341-366. University Press of Florida, Gainesville.

2010 Death and Chocolate: The Significance of Cacao Offerings in Ancient Maya Tombs and Caches at Copan, Honduras. In Pre-Columbian Foodways: Interdisciplinary Approaches to Food, Culture, and Markets in Ancient Mesoamerica, edited by J. E. Staller and M. Carrasco, pp. 293-314. Springer, New York.

Martin, Simon

2006 Cacao in Ancient Maya Religion: First Fruit from the Maize Tree and Other Tales from the Underworld. In Chocolate in Mesoamerica: A Cultural History of Cacao, edited by Cameron L. McNeil, pp. 154-183. University Press of Florida, Gainesville.

Michelon, Oscar (editor)

1976 Diccionario de San Francisco. Bibliotheca Linguistica Americana II. Akademische Druck- und Verlagsanstalt, Graz.

Miller, Mary E.

1999 Maya Art and Architecture. Thames and Hudson, New York and London.

Miller, Mary, and Simon Martin

2004 Courtly Art of the Ancient Maya. National Gallery of Art, Washington, DC

Mora-Marín, David

2001 The Grammar, Orthography, Content, and Social Context of Late Preclassic Mayan Portable Texts. Ph.D. dissertation, Department of Anthropology, State University of New York, Albany.

2003 Historical Reconstruction of Mayan Applicative and Antidative Constructions. International Journal of American Linguistics 69:186-228.

2004 The Preferred Argument Structure of Classic Lowland Mayan Texts. In The Linguistics of Maya Writing, edited by S. Wichmann, pp. vi. University of Utah Press, Salt Lake City.

2008 Full Phonetic Complementation, Semantic Classifiers, and Semantic Determinatives in Ancient Mayan Hieroglyphic Writing. Ancient Mesoamerica 19:195-213.

Olsen, Bjornar

2003 Material Culture After Text: Remembering Things. Norwegian Archaeological Review 36:87-104.

2007 Keeping Things at Arm's Length: A Genealogy of Asymmetry. World Archaeology 39:579-588.

Pío Pérez, Juan

1866-1877 Diccionario de la Lengua Maya. Juan F. Molina Solís, Merida.

Powis, Terry G.

2002 An Interfrative Approach to the Analysis of the Later Preclassic Cermaics at Lamani, Belize. Ph.D. dissertation, Department of Anthropology, University of Texas, Austin.

Powis, Terry G., and David Cheetham

200716 from House to Holy: Formative Development of CivicCeremonial Architecture in the Maya Lowlands. Research Reports in Belizean Archaeology 4:177.

Powis, Terry G., Ann Cyphers, Nilesh W. Gaikwad, Louis Grivetti, and

Kong Cheong

2011 Cacao Use and the San Lorenzo Olmec. Proceedings of the National Academy of Sciences 108:8595-8600.
Powis, Terry, Linda Howie, and Elizabeth Graham

2006 Compositional and Stylistic Variability of Late Preclassic and Protoclassic Ceramics at Lamanai, Belize. In Archaeological Investigations in the Eastern Maya Lowlands: Papers of the 2005 Belize Archaeology Symposium, edited by John Morris, Sherilyne Jones, Jaime Awe and Christophe Helmke, pp. 143-160. Institute of Archaeology, National Institute of Culture and History, Belmopan.

Powis, Terry G., W. Jeffery Hurst, María del Carmen Rodríguez, Ponciano Ortíz C., Michael Blake, David Cheetham, Michael D. Coe, and John G.

Hodgson

2007 Oldest Chocolate in the New World. Antiquity 81:302-305.

2008 The Origins of Cacao Use in Mesoamerica. Mexicon 30:35-38.

Preucel, Robert W.

2016 Pragmatic Archaeology and Semiotic Mediation. Semiotic Review 4:85-96.

Preucel, Robert W., and Alexander A. Bauer

2001 Archaeological Pragmatics. Norwegian Archaeological Review 34:85-96.

Rathje, William L.

2002 The Nouveau Elite Potlatch: One Scenario for the Monumental Rise of Early Civilizations. In Ancient Maya Political Economies, edited by M. A. Masson and D. A. Freidel, pp. 31-40. AltaMira Press, Walnut Creek.

Reents-Budet, Dorie

2006 The Social Context of 'Kawkaw' Drinking among the Ancient Maya. In Chocolate in Mesoamerica: A Cultural History of Cacao, edited by Cameron L. McNeil, pp. 202-223. University Press of Florida, Gainsville.

Reents-Budet, Dorie, Joseph W. Ball, Duke University Museum of Art, and

Jay I. Kislak Reference Collection (Library of Congress)

1994 Painting the Maya Universe: Royal Ceramics of the Classic Period. Duke University Press and Duke University Museum of Art, Durham.

Reents-Budet, Dorie, and Ronald L. Bishop

1998 Investigaciones químicas de la cerámica monocroma negra del período clásico de Calakmul, Campeche. Paper presented at the IV Congreso Internacional de Mayistas, Antigua, Guatemala.

Reents-Budet, Dorie, Ronald L. Bishop, Jennifer T. Taschek, and Joseph W. Ball

2000 Out of the Palace Dumps: Ceramic Production and Use at Buenavista Del Cayo. Ancient Mesoamerica 11:99-121.

Reents-Budet, Dorie, Sylviane Boucher-Le Landais, Ronald Bishop, and M. James Blackman

2010 Codex-style Ceramics: New Data Concerning Patterns of Production and Distribution. Paper presented at the XXIV Symposium of Archaeological Investigations, Guatemala City.

Rice, Prudence M.

1987 Pottery Analysis: A Sourcebook. University of Chicago Press, Chicago.

1989 Ceramic Diversity, Production, and Use. In Quantifying Diversity in Archaeology, edited by R. D. Leonard and G. T. Jones, 109-117. Cambridge University Press, Cambridge.

1996 Recent Ceramic Analysis: 1, Function, Style, and Origins. Journal of Archaeological Research 4:133-163.

2009 Late Classic Maya Pottery Production: Review and Synthesis. Journal of Archaeological Method and Theory 16:117-156.

Rice, Prudence M., and Donald S. Rice

2009 The Kowoj: Identity, Migration, and Geopolitics in Late Postclassic Petén, Guatemala. University Press of Colorado, Boulder. Sachse, Frauke

2008 Over Sidtant Waters: Places of Origin and Creation in Colonial K'iche'an Sources. In Pre-Columbian Landscapes of Creation and Origin, edited by John E. Staller, pp. 123-160. Springer, New York.

Scheele, Marcel

2006 Function and Use of Technical Artefacts: Social Conditions of Function Ascription. Studies in History and Philosophy of Science Part A 37:23-36.

Schiffer, Michael B.

1987 Formation Processes of the Archaeological Record. 1st ed University of New Mexico Press, Albuquerque.

1988 The Effects of Surface Treatment on Permeability and Evaporative Cooling Effectiveness of Pottery. In Proceedings of the 26th International Archaeometry Symposium, edited by R. M. Farquhar, 
R. G. V. Hancock, and L. A. Pavlish, pp. 23-29. Archaeometry Laboratory, Department of Physics, University of Toronto, Toronto.

Serres, Michel

1987 Statues. Bourin, Paris.

Shanks, Michael

2007 Symmetrical Archaeology. World Archaeology 39:589-596.

Sharer, Robert J., and Loa P. Traxler

1994 The Ancient Maya. Stanford University Press, Stanford.

Skibo, James M.

1992 Pottery Function: A Use-Alteration Perspective. In Interdisciplinary Contributions To Archaeology: Variation. Plenum Press, New York.

Stern, Ben, Carl Heron, Marcel Serpico, and Janine Bourriau

2000 A Comparison of Methods for Establishing Fatty Acid Concentration Gradients Across Potsherds: A Case Study Using Late Bronze Age Canaanite Amphorae. Archaeometry 42:399-414.

Stross, Brian

2006 Maize in Word and Image in Southeastern Mesoamerica. In Histories of Maize: Multidisciplinary Approaches to the Prehistory, Linguistics, Biogeography, Domestication, and Evolution of Maize, edited by John E. Staller, Robert H. Tykot and Bruce F. Benz, pp. 578-597. Elservier/Academic Press, Amsterdam.

Stuart, David

1988 The Rio Azul Cacao Pot: Spigraphic Observations on the Function of a Maya Ceramic Vessel. Antiquity 62:153-157.

1989 Hieroglyphs on Maya Vessels. In The Maya Vase Book: A Corpus of Rollout Photographs of Maya Vases, Vol. 1, edited by Justin Kerr and Michael D. Coe, pp. 149-160. Kerr Associates, New York.

1995 A Study of Classic Mayan Inscriptions. Ph.D. dissertation, Department of Anthropology, Vanderbilt University, Nashville.

1998 "The Fire Enters His House": Architecture and Ritual in Classic

Maya Texts. In Function and Meaning in Classic Maya Architecture,

Vol. 17, edited by Stephen D. Houston, pp. 373-425. Dumbarton Oaks Research Library and Collection, Washington, DC.

2005 Glyphs on Pots, Decoding Classic Maya Ceramics. In Sourcebook for the 29th Maya Hieroglyphic Forum, March 11-16, pp. 108-165. Department of Art and Art History, The University of Texas at Austin, Austin.

2006 The Language Of Chocolate: References to Cacao on Classic Maya Drinking Vessels. In Chocolate in Mesoamerica: A Cultural History of Cacao, edited by Cameron L. McNeil, pp. 184-201. University Press of Florida, Gainesville.
Tedlock, Dennis

1996 Popol Vuh: The Definitive Edition of the Mayan Book of the Dawn of Life and the Glories of Gods and Kings. Simon and Schuster, New York.

2002 How to Drink Chocolate from a Skull at a Wedding Banquet. RES Anthropology and Aesthetics 42:166-179.

Tokovinine, A., and V. Fialko

2007 Stela 45 of Naranjo and the Early Classic Lords of Sa'aal. PARI Journal 7:114.

Townsend, Richard F.

2000 The Aztec. Revised ed. Thames and Hudson, London.

Tozzer, Alfred M.

1941 Landa's Relacion de las cosas de Yucatan: A Translation. Peabody Museum of American Archaeology and Ethnology, Harvard University, Cambridge, MA

Trigger, Bruce

1990 Monumental Architecture: A Thermodynamic Explanation of Symbolic Behavior. World Archaeology 22:119-132.

Vaesen, Krist, and Melissa van Amerongen

2008 Optimality vs. Intent: Limitations of Dennett's Artifact Hermeneutics. Philosophical Psychology 21:779-797.

Vail, Gabrielle

2009 Cacao Use in Yucatan Among the Pre-Hispanic Maya. In Chocolate: History, Culture, and Heritage, edited by Louis E. Grivetti and Howard-Yana Shapiro, pp. 3-17. Wiley and Sons Inc., Hoboken.

Valdés, Juan Antonio

1997 Tamarindito: Archaeology and Regional Politics in the Petexbatun Region. Ancient Mesoamerica 8:321-335.

Witmore, Christopher L.

2007 Symmetrical Archaeology: Excerpts of a Manifesto. World Archaeology 39:546-562.

Wylie, Alison

1989 Archaeological Cables and Tacking: The Implications of Practice for Bernstein's "Options Beyond Objectivism and Relativism." Philosophy of the Social Sciences 19:1-18.

Young, Lisa C., and Tammy Stone

1990 The Thermal Properties of Textured Ceramics: An Experimental Study. Journal of Field Archaeology 17:195-203.

Zagorevski, Dmitri V., and Jennifer A. Loughmiller-Newman

2012 The Detection of Nicotine in a Late Mayan Period Flask by Gas Chromatography and Liquid Chromatography Mass Spectrometry Methods. Rapid Communications in Mass Spectrometry 26:403-411. 